\title{
Sustainable early design exploration of mid-rise office buildings with different subsystems using comparative life cycle assessment
}

\author{
Mohsen Zaker Esteghamati ${ }^{1}$, Houri Sharifnia ${ }^{2}$, Diep Ton ${ }^{3}$, Patricia Asiatco ${ }^{3}$, Georg Reichard ${ }^{4}$, and \\ Madeleine M. Flint ${ }^{4}$ \\ 1 Postdoctoral Associate, Department of Civil and Environmental Engineering, Virginia Polytechnic and \\ State University, Blacksburg, VA \\ 2 PhD Candidate, Department of Building Construction, Virginia Polytechnic and State University, \\ Blacksburg, VA \\ 3 Undergraduate Research Assistant, Department of Civil and Environmental Engineering, Virginia \\ Polytechnic and State University, Blacksburg, VA \\ 4 Professor, Department of Building Construction, Virginia Polytechnic and State University, Blacksburg, \\ VA \\ 5 Affiliate, Department of Civil and Environmental Engineering Virginia Polytechnic and State University, \\ Blacksburg, VA
}

\begin{abstract}
Minimizing environmental impacts over a building's life cycle is critical to achieving sustainable communities. Early design is the most critical step to improve construction's sustainability, as the majority of important decisions have not yet been made. However, the implementation of sustainability assessment in early design is data- and effort-intensive, resulting in limited whole building life cycle assessments. Previous studies have mainly focused either on single residential structures, included only a subset of building components, or investigated early design parameters mostly associated with energy efficiency. Whereas, comparison of alternative building subsystems at early design received less attention. This study aims to provide and utilize benchmark data for the life-cycle impacts of mid-rise office buildings, focusing on the impact of building subsystem selection at early design exploration. Environmental impacts were compared across six professionally-designed archetypes comprising compatible combinations of foundation, floor, and structural assemblies for a site in Charleston, South Carolina. Detailed operational energy modeling was performed using the EnergyPlus framework, where a range of code-compliant envelope systems are studied and paired with other assemblies. Lastly, sensitivity assessment and statistical analysis are performed to quantify uncertainty associated with the use of such data for early design guidance. The results suggest that decisions associated with the use phase (such as envelope selection) dominates life cycle impacts and should be prioritized. Additionally, no single subsystem governs all embodied impacts across different buildings. Lastly, it is critical to consider a large number of alternatives at the early design stage, as excluding a combination of subsystems might close pathways to reaching a more environmentally suitable alternative during design iterations/optimization.
\end{abstract}

Keywords: Sustainability · Life cycle assessment · Energy modeling · Early Design · Office buildings performance

\section{Introduction}

Sustainable construction encompasses all the processes and choices that improve both present and future environmental, social and economic needs, referred to as the "triple bottom line (TBL)" [1, while maintaining construction's quality at different phases of the project [2]. Although sustainable construction is acknowledged as an emerging field [3], it has still not become standard practice [4, 5]. Economic needs often dominate construction practice, and the two other pillars of sustainability are 
treated as additional goals, rather than a necessary concern to shape stakeholders' decisions [6]; even though the building sector uses $30 \%$ and $40 \%$ of the world's raw material and energy, and produces $33 \%$ of global greenhouse gas emissions [7. Among the main barriers to standardizing sustainable construction are the resource and time intensiveness of data collection, the complexity of analysis, and lack of demand from clients 8 11. To this end, sustainable construction requires a holistic approach [12, 13] to balance individual, construction, and community needs.

Early design is the most influential piece to achieve sustainable construction [14? -16, as decisions made at this stage have the highest potential to shape building life cycle performance [14. Bunz et al. surveyed sustainable construction practices of North America, Europe and Asia, and suggested that while all different stages of the building life cycle will benefit from implementing sustainability principles, early design is of utmost importance [17. Basbagil et al. demonstrated that early design decisions are essential to achieve environmental-friendly solutions. They showed that choosing materials with the lowest embodied impacts in each building subsystem (envelope, interior, and structure) can reduce more than $50 \%$ of the total embodied impacts of the final design [18.

Despite the importance of early design, limited research has addressed the implementation of sustainability in this stage using quantitative frameworks such as life cycle assessment (LCA) [19, 20]. The reason behind this shortcoming is that early design is highly uncertain and fast-paced [21], where the complexity of design space, data incompleteness, and the iterative nature of the design process further hinder the implementation of quantitative frameworks. Therefore, while other industries (such as automotive) have a fair history of integrating environmental aspects into the design process through "life cycle design" or "eco-design" 22, 23, the construction industry has yet to embrace the sustainable design concept. A recent survey on 16 architectural firms showed that the majority did not use any LCA tools in the design process, and would hire a consultant for energy modeling, if it is strictly needed [24].

Machine learning (ML) is a viable solution to address the challenges of sustainability integration in early design [25. ML algorithms can employ large datasets to extract relationships between different design variables and the estimated environmental impacts. The first step in ML application is to develop environmental whole-building LCAs performance inventories for different buildings' taxonomies [26, 27]. Out of the relatively few whole-building LCAs available in the literature, significant discrepancies exist between the scope and goals of these studies (e.g. building type, included life-cycle stages, methodological choices), which lead to inefficiency and/or infeasibility of ML algorithms.

A review of 250 case studies 28. emphasizes that the most pressing issue in application of LCA data is the lack of transparency regarding assessment choices, namely, clearly outlined functional unit, service life, gross floor area, and data sources. Moreover, previous scarce whole-building LCAs mainly focused on residential superstructures and studied variations in envelope and climate [29, 30, material [31, construction techniques [32, insulation [33, 34], or renovation [35], whereas comparison between different building subsystems received less attention. However, for most real-life projects, the building's topology (in terms of building height and area) is already decided by other project constraints, and subsystems' selection (e.g. type of foundation, structural system) precedes other early design decisions.

This study provides LCAs of six archetype office buildings with different foundation, structural, floor, and envelope systems to compare the impact of subsystem selection on the environmental performance of a commercial building project. Subsequently, sensitivity assessments are performed on operational and embodied impacts to determine the most influential subsystems to shape early design decisions. Lastly, a meta-analysis of results is performed to compare calculated impacts to available data from the literature, and to infer early design guidance on subsystem selection through statistical methods, namely t-test and Bayesian analysis. An important feature of this LCA study is that unlike other whole building LCAs, the variations in subsystems other than structure (i.e. foundation, floor, envelope) are considered and paired with detailed operational energy modeling specific to the building archetype, while keeping the analysis boundary, scope and method consistent. Therefore, the LCA models and data of this study (publicly available at [36]) are expected to address 
the severe shortcoming of accessible, standardized, and transparent whole-building LCA data to train future ML algorithms. Additionally, the focus on subsystem variability provides insight for engineers who intended to perform holistic designs capturing environmental performance in conjunction with other performance measures such as integrity and resistance to natural hazards.

\section{Background}

\subsection{Office building LCAs}

The construction industry has widely used LCA in recent years to: (1) select environmentallyfriendly construction products, (2) evaluate building systems and construction processes, (3) develop industry-specific software and databases; a comprehensive review of these applications can be found in a study by Cabeza et al. 37. Despite the large number of studies using LCA for different purposes, most building LCAs focused on residential buildings rather than commercial ones, as noted by several authors [38, 39. Additionally, these studies adopted limited sustainability indicators (e.g. energy use, global warming potential), disregarded certain life cycle stages, addressed only specific building components [39, 40, and lack sensitivity assessments. Khasreen et al. assembled published LCA in the building sector from 1995 to 2009 and showed that two-third focused on material and component combination and only one-third focuses on whole-building performance. A similar conclusion is made by other literature review studies [41].

Table 1 summarizes the available whole building LCA studies on office buildings that meet a minimum threshold for analysis details. Even with the same thresholds, the difference in scope and analysis methods of current LCA studies hampers a conclusive comparison [7. However, two major findings exist in the literature. First, energy use dominates the environmental impact of typical residential and non-residential buildings. A review of published LCAs including energy use shows that $62 \%$ to $98 \%$ of total impacts are because of energy use 42. Second, material selection impacts the embodied phase [7, although the scarcity of available studies impedes determining the most environmentally-friendly material and systems. A study on residential buildings showed that replacing steel with wood resulted in $0.06-0.88 \mathrm{~kg}$ reduction in $\mathrm{CO} 2$-eq per $\mathrm{kg}$ wood, whereas replacing concrete with wood yielded $0.16-1.77 \mathrm{~kg}$ reduction of $\mathrm{CO} 2$-eq per $\mathrm{kg}$ wood [43]. Another study on two steel and two concrete framing options concluded that the steel designs have the lowest global warming potential, smog, and human health respiratory effects [4].

\subsection{Early design}

Early design consists of alternating phases of divergence and convergence [53, 54]. At divergence, the design space is populated with promising alternatives, whereas at the following convergence phase those alternatives are evaluated to achieve a set of feasible alternatives that meet stakeholders' needs 43. Both phases are repeated until all existing considerations and new requirements are satisfied, and a few designs remain for further detailed assessment. The hunt for the solution "treasure" in the unmapped and unexplored territory of the design problem is unaided, and often finding more solutions clarifies the design problem, backtracking to a new set of possible solutions [45].

Holistic integrated design and performance optimization are not commonly considered at preliminary stages [55, where early design of buildings is often shaped by engineering intuition, designer prior experience, and project's economic constraints. A past survey showed that early decisions on building geometry and orientation are impacted by site location and zoning ordinances, whereas decisions on structural and envelope systems are influenced by project pricing [24. Among the limited efforts, Gagnon et al. compared holistic and sequential design for a residential building using 39 design variables (mostly associated with envelope system) and three objectives of cost, thermal comfort and greenhouse gas emission [55]. Bernett et al. developed an early design decision-making framework to generate schematic designs that are ranked based on energy use, embodied carbon 
Table 1: Summary of whole building office LCA studies

\begin{tabular}{|c|c|c|c|c|c|c|c|c|}
\hline ReferenceYear & $\begin{array}{l}\text { Flr } \\
\text { No. }\end{array}$ & $\begin{array}{l}\text { Flr } \\
\text { area } \\
\left(m^{2}\right)\end{array}$ & Location & $\begin{array}{l}\text { Life } \\
\text { span }\end{array}$ & $\begin{array}{l}\text { Life } \\
\text { cycles }\end{array}$ & $\begin{array}{l}\text { Analysis } \\
\text { typ. }\end{array}$ & $\begin{array}{l}\text { Structural } \\
\text { sys. }\end{array}$ & $\begin{array}{l}\text { Other } \\
\text { subsys. }\end{array}$ \\
\hline $\begin{array}{l}\text { Scheuer et } 2003 \\
\text { al. } 45\end{array}$ & 6 & 7300 & $\begin{array}{l}\text { Ann Ar- } \\
\text { bor, USA }\end{array}$ & 75 & All & $\begin{array}{l}\text { Process-based } \\
\text { (Different } \\
\text { data) }\end{array}$ & Ste & $\begin{array}{l}\text { Envelope, } \\
\text { Interior }\end{array}$ \\
\hline $\begin{array}{l}\text { Guggemos } 2005 \\
\& \text { Hovath } \\
46\end{array}$ & 5 & 4400 & $\begin{array}{l}\text { Midwest } \\
\text { USA }\end{array}$ & 50 & All & Process-based & $\begin{array}{l}\text { Steel frame, } \\
\text { Concrete frame }\end{array}$ & $\begin{array}{l}\text { Foundation, } \\
\text { Envelope, } \\
\text { interior }\end{array}$ \\
\hline $\begin{array}{l}\text { Junnila et } 2006 \\
\text { al. } 47\end{array}$ & 4 & 4400 & $\begin{array}{l}\text { Finland, } \\
\text { Midwest } \\
\text { USA }\end{array}$ & 50 & All & EIO method & $\begin{array}{l}\text { Concrete } \\
\text { frame, Con- } \\
\text { crete frame and } \\
\text { core shear wall }\end{array}$ & $\begin{array}{l}\text { Foundation, } \\
\text { Envelope, } \\
\text { interior }\end{array}$ \\
\hline $\begin{array}{l}\text { Kofoworola2008 } \\
\& \quad \text { Ghee- } \\
\text { wala } 48 \text { ] }\end{array}$ & & 60000 & Thailand & 50 & All & Combined & Concrete & $\begin{array}{l}\text { Foundation, } \\
\text { Envelope }\end{array}$ \\
\hline $\begin{array}{l}\text { Diamoudi } 2008 \\
\& \text { Tompa } \\
\text { 49 }\end{array}$ & 5,3 & $\begin{array}{l}1891 \\
400\end{array}$ & $\begin{array}{l}\text { Athens, } \\
\text { Greece }\end{array}$ & - & Embodied & LCI & $\begin{array}{l}\text { Concrete frame } \\
- \text { walls system }\end{array}$ & $\begin{array}{l}\text { Foundation, } \\
\text { Envelope }\end{array}$ \\
\hline $\begin{array}{l}\text { Stek et al. } 2011 \\
44\end{array}$ & 4 & 11613 & $\begin{array}{l}\text { Chicago, } \\
\text { USA }\end{array}$ & 50 & All & $\begin{array}{l}\text { Process-based } \\
\text { (ATHENA) }\end{array}$ & $\begin{array}{l}\text { Steel frame, } \\
\text { RC frame- wall, } \\
\text { RC column and } \\
\text { wall with } \\
\text { post-tensioned } \\
\text { beams, Steel } \\
\text { braced frame }\end{array}$ & $\begin{array}{l}\text { Foundation, } \\
\text { Envelope }\end{array}$ \\
\hline $\begin{array}{l}\text { Robertson } 2012 \\
\text { et al. } 50 \text {. }\end{array}$ & 5 & 14233 & $\begin{array}{l}\text { Burnaby, } \\
\text { Canada }\end{array}$ & - & $\begin{array}{l}\text { Production } \\
\text { construc- } \\
\text { tion }\end{array}$ & $\begin{array}{l}\text { Process-based } \\
\text { (ATHENA, } \\
\text { BEES) }\end{array}$ & $\begin{array}{l}\text { Timber frame, } \\
\text { RC frame }\end{array}$ & $\begin{array}{l}\text { Foundation, } \\
\text { Envelope }\end{array}$ \\
\hline $\begin{array}{l}\mathrm{Wu} \text { et al. } 2012 \\
51\end{array}$ & 13 & 36500 & $\begin{array}{l}\text { Dalian, } \\
\text { China }\end{array}$ & 50 & All & $\begin{array}{l}\text { Process-based } \\
\text { (Different } \\
\text { data) }\end{array}$ & Concrete & Envelope \\
\hline $\begin{array}{ll}\text { Feese } & \text { et } 2014 \\
\text { al. 52 } & \end{array}$ & 4 & 8027 & $\begin{array}{l}\text { Los Ange- } \\
\text { les, USA }\end{array}$ & 60 & All & $\begin{array}{l}\text { Process-based } \\
\text { (ATHENA) }\end{array}$ & $\begin{array}{l}\text { Steel frame, } \\
\text { Concrete frame }\end{array}$ & \\
\hline
\end{tabular}

and construction cost [56. Similar multi-objective optimization approach is used to balance HVAC energy cost and occupants comfort [57, envelope design by energy use, environmental and financial cost [58, and envelope design variables based on operational and embodied energy [59]. The reviewed literature emphasizes that a framework incorporating holistic early design in building subsystems selection is still missing.

\subsection{Data-driven LCA}

ML algorithms are increasingly applied at different stages of design, however, limited studies implemented them at the early design stage for LCA assessments. Most efforts on data-driven LCAs are directed at application of ML algorithms to predict the energy performance of specific building geometries. Some authors proposed surrogate models for environmental impact evaluation. Hester et al. developed regression models from the results of detailed analytical models and demonstrated that it can rapidly parametrize the early design space for energy performance evaluation 60. Chen et al. developed several regression-based surrogate models such as multivariate adaptive regression splines to predict the indoor quality of a passively designed high-rise building [61]. $\mathrm{Ng}$ et al. used ant colony optimization to evaluate LCA of multiple design variations 62. 
Several studies used ML in conjunction with building information models (BIM) for design optimization. Inyim et al. developed a simulation tool to leverage BIM capabilities and optimization algorithms in an integrated fashion for satisfying several objectives in terms of construction time, initial construction cost, and $\mathrm{CO} 2$ emission [4. Gan et al. used the genetic algorithm to alter structural topology and member sizing to reduce embodied carbon emission and construction cost of a concrete high-rise building [63. In addition, several data-driven workflows are proposed to integrate LCA in BIMs [64, 65, although this process is not yet streamlined for design due to technical (e.g. harmonization and data sources) and organizational issues [66, 67.

A prominent application of ML is to quantify sustainability indicators' uncertainties in respect to design variability. Feng et al. use parametric design to create a database of early design scenarios where they applied an integrated fuzzy C-means clustering and extreme learning machine (ELM) algorithms to quantify the resultant environmental metrics' uncertainties [68]. Lu et al. performed a reliability-based energy optimization of an office building considering envelope and occupancy parameters' uncertainties [29]. Hester et al. proposed a streamlined probabilistic LCA framework using building attributes, where early design uncertainty is characterized by the available level of detail and the resultant variability in impact is measured through Monte Carlo simulation. Subsequently, a sensitivity assessment identifies attributes that require additional specifications to reduce variability in predicted impact [19].

\subsection{Research gaps \& Contributions}

1. A building consists of compatible foundation, structural (both gravity and lateral-resisting), and envelope subsystems. Therefore, focusing on a single subsystem does not accurately represent buildings' environmental performance. In contrast, this study aims to exploit previously identified archetype commercial constructions [69 to explore how the synergies between different compatible subsystems determine buildings' embodied and operational impacts.

2. Current practice uses prior experience and economic constraints for building subsystem selection at early design, where environmental performance is often overlooked in this process. This study investigates the environmental impact of different subsystems and aims to answer whether there is a meaningful difference between possible alternatives that cannot be

3. Current ML-based LCA studies are focused on model development and optimization for a specific design, whereas generating data-driven LCA solutions require open data inventories that are transparent and derived consistently for different building systems. This study provides LCA data for a wide variety of building systems, is consistently obtained following standard ISO method, and can be accessed through a public repository [36.

\section{Sustainability performance assessment}

This section focuses on the environmental aspect of sustainability performance, taking into account the material resources and energy use as environmental input and emission and waste as the output. A whole-building LCA is carried out following the four-staged methodology described in ISO14040 [70], where analysts must (a) define LCA goal and scope, (b) develop life cycle inventory, (c) assess life cycle impacts, and finally (d) interpret the results.

\subsection{Goal and Scope}

This study aims to establish a comparative LCA benchmark for six alternative designs of a midrise office building in terms of foundation, structural and envelope systems selection for a site in Charleston, South Carolina. The results will quantify the role of early design decisions associate with subsystem selection on commercial buildings' environmental impacts and provide a baseline data to facilitate the application of future ML algorithms in the early design of office buildings. 
3.1.1 Archetype buildings Six design alternatives (referred to as archetype buildings) were considered for a hypothetical office building located in Charleston, South Carolina (32.722105, 79.93408). All archetypes have identical plan and elevation layout, comprising four floors with 6 bays at 30 feet $(54.86 \mathrm{~m})$ each in the longitudinal direction and 3 bays at 30 feet $(27.43 \mathrm{~m})$ in the transverse direction, for a total of 64,800 square feet $(19751.04 \mathrm{~m} 2)$ of usable space. While using the same plan layout, building height and orientation remove some important early decisions from this study's design space, it allows for a consistent comparison of less explored decisions associated with subsystem and material selection. This is also in line with previous studies showing that building general geometry is dictated by project constraints [71] such as zoning, which is often beyond early design decisions made by the construction team. The archetypes' design (foundation, floor and structural systems) was conducted by a professional engineering firm to represent real construction practice that meets building codes requirements. Following Charleston Board of Architectural Review (BAR) regulation, a combination of brick masonry, stucco, precast concrete panels, and architectural glass/glazing have been included as exterior envelope systems. Figure 1 shows the plan and 3D view of the studied buildings, which include concrete (frame, wall), steel (frame, braced), masonry, and wood designs. Table 2 shows the selected alternatives for subsystems of each design. For brevity, archetype buildings will be referred to by their corresponding lateral system (designated name in Table 2) hereafter. Additional data and building information models (BIMs) of the archetypes can be found in a supporting repository 69 .

3.1.2 System boundary Figure 2 shows the system boundary for each archetype along production, construction, operation, and end-of-life (EOL). The system boundary is consistent with EN15804/15978 [72]. The production phase consists of raw material (e.g. iron ore, aggregate) extraction, manufacturing, assembly of building products, and transportation of finished products to the construction site. The amount of material used is obtained from design documents and BIMs.

Table 2: Description of SFSE systems of the archetype buildings

\begin{tabular}{|c|c|c|c|c|c|}
\hline ID & Name & Foundation & Structural sys. & $\begin{array}{l}\text { Envelope } \\
\text { sys. }^{\text {b }}\end{array}$ & Floor sys. \\
\hline$\overline{\mathrm{U}-\mathrm{M}-}$ & Steel & Matt foundation on & Steel buckling restrained & Window Wall & Composite steel deck: $61 / 4 "$ \\
\hline $\begin{array}{l}\text { SBRB- } \\
\text { GCW }\end{array}$ & $\mathrm{BRB}$ & $\begin{array}{l}\text { unimproved } \text { soil }^{\mathrm{a}} \& \\
\text { 4"slab on grade }\end{array}$ & braced frames & & $\begin{array}{l}\text { lightweight concrete slab } \\
\text { and 2" galvanized steel deck }\end{array}$ \\
\hline $\begin{array}{l}\mathrm{U}-\mathrm{C}- \\
\mathrm{RMSW}- \\
\mathrm{B} / \mathrm{CMU}\end{array}$ & $\begin{array}{l}\text { Masonry } \\
\text { wall }\end{array}$ & $\begin{array}{l}\text { Matt foundation on } \\
\text { unimproved soil \& } \\
\text { 4"slab on grade }\end{array}$ & $\begin{array}{l}\text { Special reinforced ma- } \\
\text { sonry shear wall }\end{array}$ & $\begin{array}{l}\text { Brick / Block } \\
\text { Backup }\end{array}$ & $\begin{array}{l}\text { Precast hollow core planks } \\
\text { and } 2 " \text { normal weight con- } \\
\text { crete slab }\end{array}$ \\
\hline $\begin{array}{l}\text { U-C- } \\
\text { WSW- } \\
\text { S/SS }\end{array}$ & $\begin{array}{l}\text { Wood } \\
\text { wall }\end{array}$ & $\begin{array}{l}\text { Strip foundation on } \\
\text { unimproved soil \& } \\
\text { 4"slab on grade }\end{array}$ & $\begin{array}{l}\text { Light-Framed wood } \\
\text { walls sheathed \& } \text { wood } \\
\text { structural panels }\end{array}$ & $\begin{array}{l}\text { CLT / Wood } \\
\text { stud }\end{array}$ & $\begin{array}{l}\text { Wood truss with plywood } \\
\text { decking }\end{array}$ \\
\hline $\begin{array}{l}\text { U-S- } \\
\text { SMRF- } \\
\text { GCW }\end{array}$ & $\begin{array}{l}\text { Steel } \\
\text { frame }\end{array}$ & $\begin{array}{l}\text { Spread footings on } \\
\text { improved ground and } \\
\text { 4"slab on grade }\end{array}$ & $\begin{array}{l}\text { Steel special moment- } \\
\text { resisting frames }\end{array}$ & Window Wall & $\begin{array}{l}\text { Composite steel deck: } 61 / 4 " \\
\text { lightweight concrete slab } \\
\text { and } 2 \text { "galvanized steel deck }\end{array}$ \\
\hline $\begin{array}{l}\text { U-S- } \\
\text { RCMRF- } \\
\text { B/CMU }\end{array}$ & $\begin{array}{l}\text { Concrete } \\
\text { frame }\end{array}$ & $\begin{array}{l}\text { Spread foundation on } \\
\text { unimproved soil and } \\
\text { 4"slab on grade }\end{array}$ & $\begin{array}{l}\text { Special } \mathrm{RC} \text { moment- } \\
\text { resisting frame }\end{array}$ & $\begin{array}{l}\text { Brick / Block } \\
\text { Backup }\end{array}$ & \\
\hline $\begin{array}{l}\text { U-S- } \\
\text { RCSW- } \\
\text { GCW }\end{array}$ & $\begin{array}{l}\text { Concrete } \\
\text { wall }\end{array}$ & $\begin{array}{l}\text { Spread foundation on } \\
\text { unimproved soil and } \\
\text { 4"slab on grade }\end{array}$ & $\begin{array}{l}\text { Special Reinforced Con- } \\
\text { crete Shear Walls }\end{array}$ & $\begin{array}{lr}\text { Stucco } & / \\
\text { Brick/ Block } \\
\text { Backup }\end{array}$ & $\begin{array}{l}\text { Two-way post-tensioned } \\
\text { concrete slabs }\end{array}$ \\
\hline
\end{tabular}

${ }^{\mathrm{a}}$ Unimproved soil assumes 2000 PSF allowable static bearing pressure, 3,000 PSF allowable transient bearing pressure, and a 60 PSI sub-grade modulus.

b (b) The envelopes are mixed type based on two envelope wall constructions. For modeling details refer to Section 3.3.1. 

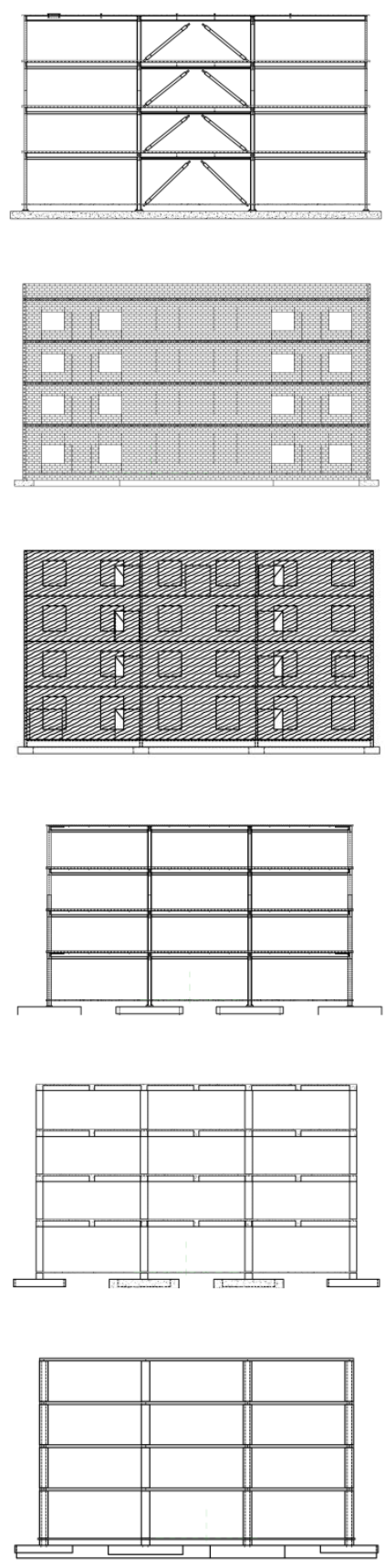

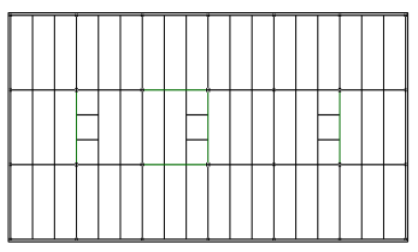

(a) steel BRB building

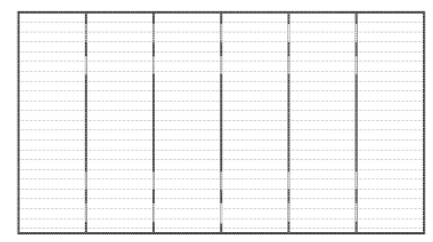

(b) Masonry wall building

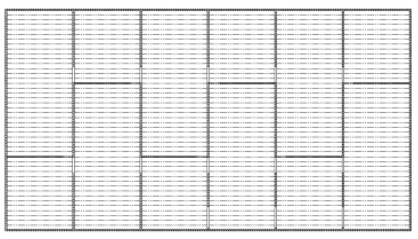

(c) Wood wall building

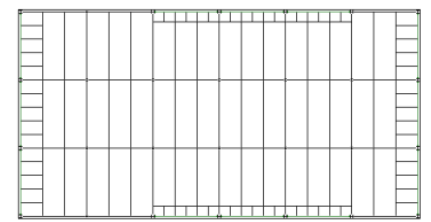

(d) Steel frame building

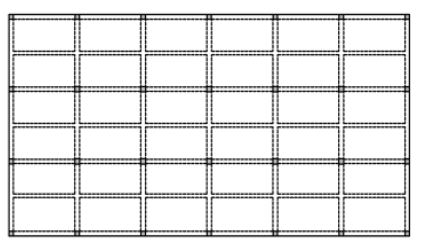

(e) Concrete frame building

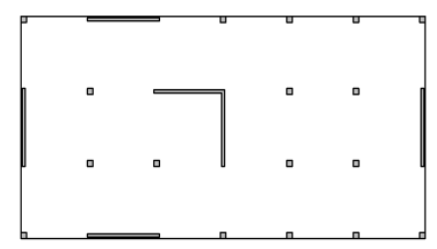

(f) Concrete wall building
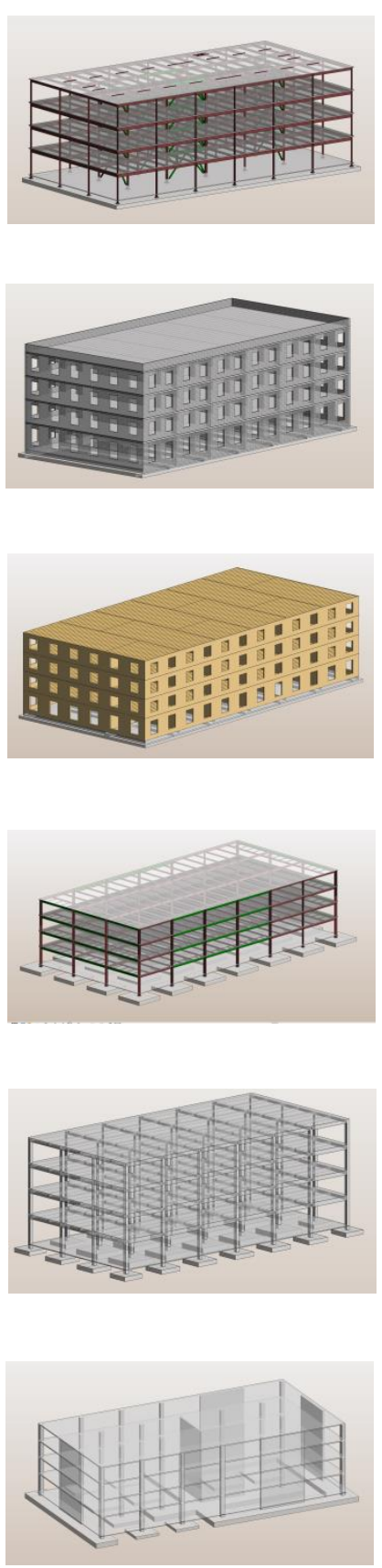

Fig. 1: Plan layout, side view, and 3D view of the considered buildings

The construction phase includes processes required to build the structure, envelope, foundation, and roofing system. Construction phase includes on-site construction such as energy used for material transportation and mechanical lift, concrete pour, formwork and rebar placement 72 . The operational phase accounts for operational energy use and recurring maintenance and replacement schedules. Maintenance and replacement schedules are applied for materials and assemblies exposed to wear (e.g., windows in envelop, gypsum boards) with a shorter service life than the building. 


\section{Building subsystems}

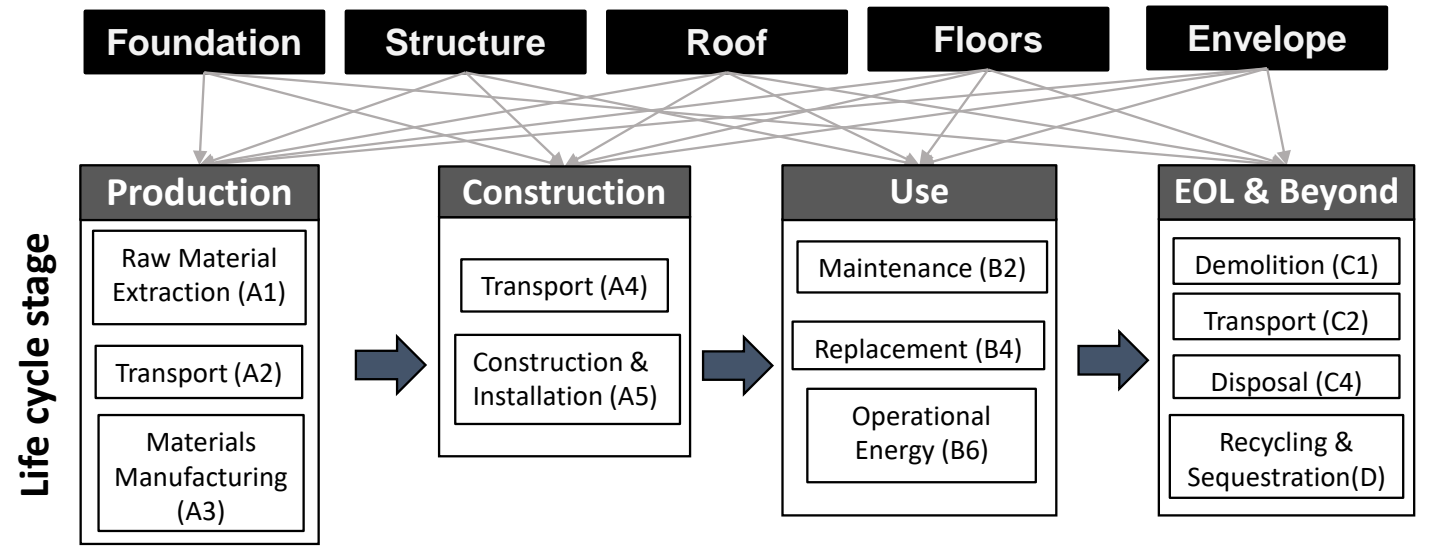

Fig. 2: The scope of LCA performed in this study

These activities include energy use, typical transportation, and on-site generated waste and its final disposition based on maintenance frequency (determined from building type and location) [72. Operational energy refers to expected energy consumption within a building determined based on HVAC and lighting. Lastly, the end of the use phase comprises demolition, transportation from site to landfill, disposal of non-recyclable materials and recycling. Certain environmental loads and benefits beyond building service life (Module D) are also considered to account for biogenic carbon sequestration and metal recycling. The LCA software (i.e., ATHENA impact estimator) uses a conservative approach for carbon sequestration, where credit (i.e. negative emission) is only given for permanently stored carbon (as opposed to carbon that will eventually be released due to decay) using the waste reduction model that can predict the amount of remained wood in the landfill in 100 years. This accounting approach is in general agreement with ISO/TC 14067 [72. ATHENA uses closed-loop recycling methodology for metals (consistent with ISO 14044), where credit is given for net steel scrap produced at end of product life. When this scrap is used in manufacturing, the avoided impacts of using alternatives or virgin metal is accounted for [72? ]. The functional unit is defined as one building with 64,800 square feet of usable area that satisfies the minimum building code and all legal requirements over a lifetime of 50 years. Several processes that are not directly related to the goal of the study are excluded from the system boundary, such as manufacturing of the factory equipment needed to produce construction products (including both equipment and building materials); the time of the AEC teams related to planning, design, and similar work; non-permanent building components (e.g. drop ceiling panels); office equipment (e.g., furniture ); and activities of the occupants and building management staff that are not related to the energy use of the MEP systems (i.e., "plug loads").

\subsection{Life cycle data inventory (LCI)}

Different data sources should be integrated to provide information on material consumption, energy use, and emission to land, water and air. All data used in this study is "secondary data", which is acquired through publications, software, and LCA libraries. The main source of data in this study is from ATHENA inventories which provide detailed and high-quality data for North America that is compatible with ISO 14040/14044 unit process LCI data. The quality of data for the important materials (the ones that made $95 \%$ of building weight) is assessed based on the following metrics 73, 74: 
1. Reliability: Evaluates data generation/collection method and whether this process was verified. The reliability of LCI data is deemed between excellent and good (i.e. score between 1 to 2, in the pedigree matrix [73]) as it is based on measured data that is sometimes verified.

2. Completeness: Determines whether the data has come from a sufficient number of samples over an adequate period of time. LCI inventory has excellent completeness (i.e. score 1) as it has regional samples from several plants in a reasonable time frame.

3. Temporal correlation: Measures the closeness of LCA analysis and LCI data collection time frames. Most of the LCI data is relatively recent (between six to 10 years old), which can be categorized as average temporal correlation (i.e. score 3).

4. Geographical correlation: Measures how well LCI data represents the building site. Since LCI uses average data from areas with similar conditions, geographical correlation can be deemed as average (i.e. score 3).

5. Technological correlation: Assess the similarity between technology used in materials of archetypes and LCI data sources. While technological correlation varies substantially between different material, for important materials such as concrete and steel, the LCI data have good technological correlation (i.e. score 2), as it reflects similar processes and materials, but from different enterprises.

Based on the aforementioned metrics, the geographical correlation could be a potential source of error. It should be noted that although ATHENA uses regionally sensitive data to account for the difference in technology, transportation, energy mix, and other related factors, it still uses average data for each region, and hence, a degree of discrepancy is expected for a specific site. Therefore, although the convenience of ATHENA inventory and its high quality offset the need for site-specific LCI data, it is acknowledged that some factors such as transportation and energy use for product manufacturing might be over- or under-estimated. Additional information on data sources is provided in Appendix 2.

LCI analysis shows that concrete is the most used material in all archetypes (ranging from $60 \%$ to $90 \%$ of building weight), where it is primarily used in the construction of floors for BRB, masonry, concrete frame, and shear wall building, and foundation of wood and steel frame buildings. Even in BRB and steel frame buildings, steel material accounts for $3 \%$ and $6 \%$ of building weight, respectively. Concrete masonry blocks, brick and gypsum boards, and rebar are other largely used materials. The detailed bill of most used materials is provided in Appendix 3 for all considered Archetypes.

\section{3 operational energy modeling}

Operational energy was modeled using the EnergyPlus (version 9.1.0) simulation environment. As shown in Figure 3, the building's energy simulation begins with acquiring data on project climate and architectural layout. Subsequently, a physical description of the building system (e.g. building footprint, exterior walls) is developed in Sketch Up, where interior and exterior surfaces are clearly defined. Lastly, space types, thermal zones, and construction materials are assigned using OpenStudio plugin and energy performance is simulated in EnergyPlus. Climate data from Charleston International Airport (station 772080) was used and the climate zone was defined as ASHRAE 3A. A typical climate data file includes hourly temperatures, humidity, cloud cover, etc., which are crucial for EnergyPlus to simulate the building's response to local climatic conditions. The building layout was used to determine the thermal zoning (twelve zones) and internal loads for the whole building. A window-to-wall ratio of 0.31 was considered for exterior walls, except for walls located at stairs, restrooms, elevators, print, mailroom, and small conference rooms, following the architectural advisory board comments. Since the goal of this study is limited to early design, realistic HVAC system design is deemed out of scope, however, the ideal air loads are included to account for thermal exchange, where a specified amount of outdoor air mixes with the air inside to cool/heat at $100 \%$ efficiency. Therefore, while ideal air loads consider energy use due to heating and cooling loads, it 


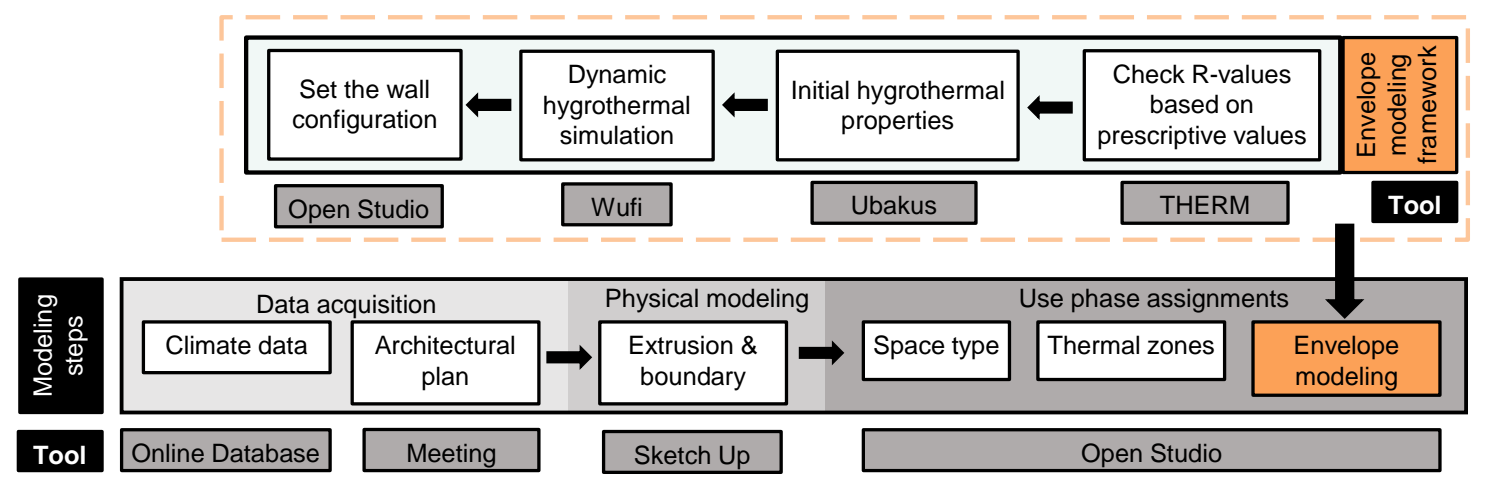

Fig. 3: Operational energy modeling framework

overestimates energy consumption because a real HVAC system will not have $100 \%$ efficiency. Based on the architectural layout, occupancy and lighting schedules were devised.

Climate data from Charleston International Airport (station 772080) was used and the climate zone was defined as ASHRAE 3A. A typical climate data file includes hourly temperatures, humidity, cloud cover, etc., which are crucial for EnergyPlus to simulate the building's response to local climatic conditions. The building layout was used to determine the thermal zoning (twelve zones) and internal loads for the whole building. A window-to-wall ratio of 0.31 was considered for exterior walls, except for walls located at stairs, restrooms, elevators, print, mailroom, and small conference rooms, following the architectural advisory board comments. Since the goal of this study is limited to early design, realistic HVAC system design is deemed out of scope, however, the ideal air loads are included to account for thermal exchange, where a specified amount of outdoor air mixes with the air inside to cool/heat at $100 \%$ efficiency. Therefore, while ideal air loads consider energy use due to heating and cooling loads, it overestimates energy consumption because a real HVAC system will not have $100 \%$ efficiency. Based on the architectural layout, occupancy and lighting schedules were devised.

Table 3: Table 3. Archetypes' envelope wall systems

\begin{tabular}{lll}
\hline Archetype name & Wall A & Wall B \\
\hline BRB & Spandrel glass wall & CMU + Brick veneer \\
Masonry wall & CMU + brick veneer & CMU + Brick veneer \\
Wood wall & Wood stud + Stucco & Wood stud + Stucco \\
Steel Fame & Spandrel glass wall & Steel stud + Stucco \\
Concrete Frame & CMU + brick veneer & CMU + Brick veneer \\
Concrete Wall & CMU + brick veneer & Shear wall + Stucco \\
\hline
\end{tabular}

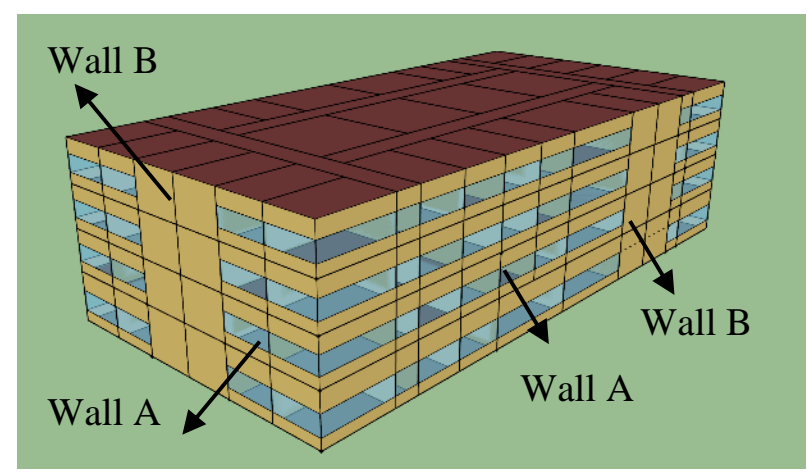

Fig. 4: Archetypes' model for energy simulation 
3.3.1 Envelope selection modeling Envelope systems are the main barriers separating interior and exterior, which control water, vapor, air, and heat transfer, and subsequently energy efficiency and human comfort. An exterior wall assembly consists of four performance layers: (a) the interaction with the structural system as either curtain or infill wall; (b) the wall support system; (c) the exterior finish; and (d) the water control method. A complete description of the envelope system's taxonomy is provided in Appendix 1. Numerous envelope systems can be defined by combining different options of each performance layer.

Figure 4 shows the model of archetype buildings, and Table 3 presents selected wall types. There are two types of envelope walls (denoted as wall A and B in Figure 4) conforming to the architectural requirements of the facade. The envelope systems are chosen based on compatibility with the archetype's structural systems, e.g. using lighter envelope systems for wood wall building, faster constructability of steel frames with steel studs, etc. Each selected envelope wall is checked to satisfy prescriptive R-values for ASHRAE 3A climate and its initial hygrothermal properties are determined. A dynamic simulation is then carried out to validate/adjust hygrothermal properties. Lastly, the designed envelope wall is added to OpenStudio and ATHENA for building energy simulation and embodied impacts assessment, respectively.

\subsection{Life cycle impact assessment}

This section presents the results of whole building LCA (WLCA) from two different perspectives: (a) the most influential life cycle stages and (b) the contribution of different building subsystems. The impact assessment measures are consistent with the "Reduction and Assessment of Chemical and Other Environmental Impacts (TRACI)" methodology [75].

3.4.1 Comparison of life cycle stages' impacts Figure 5 compares different life cycle stages' contributions for three environmental impact categories, where the left plots quantify operational (white bar) and embodied (black bar) contribution. The results reinforce the prior studies that the operational phase dominates LCA impacts of office buildings, as the operational stage contributes on average to $95 \%, 96 \%$, and $97 \%$ of global warming potential (GWP), fossil fuel consumption, and human health $(\mathrm{HH})$ particulate emission for different prototype buildings, respectively. Since similar observations can be made for other impacts, this observation indicates that to achieve more environmentally sustainable commercial buildings, early design decisions associated with operational energy use should be prioritized. It should be noted that the archetypes' operational impacts are very similar with a coefficient of variation of $0.7 \%$ for all three impacts, as code-compliant envelope systems do not show significantly different energy performance for this climate.

The right plots of Figure 5 decompose embodied impacts into the corresponding life cycle stages. Overall, the production stage has the highest contribution for all measures, contributing to an average of $92 \%, 80 \%$, and $88 \%$ of archetypes' embodied GWP, fossil fuel consumption and HH particulate emission, respectively. The contribution of construction, maintenance, and end-of-life varies depending on prototype building and considered impact. While maintenance contribution is trivial on GWP and fossil fuel consumption for all archetype buildings, it has a significant contribution to HH particulate emission of steel buildings ( $13 \%$ for both BRB braced and steel frame buildings). On the other hand, although end-of-life contributes to $16 \%$ and $15 \%$ of embodied fossil fuel consumption for the concrete frame and wall buildings, respectively, it has a negligible impact ( $i 1 \%)$ for steel buildings due to recycling that balances the environmental negative burdens.

3.4.2 Comparison of assemblies' embodied impacts The use phase dominates life stages of all archetype buildings, however, future scenarios are plausible where efficient energy-saving systems and passive controls reduce the operation's contribution to the extent of embodied stages. A survey on more than 650 buildings has shown that the embodied greenhouse gas could increase to $45-50 \%$ 


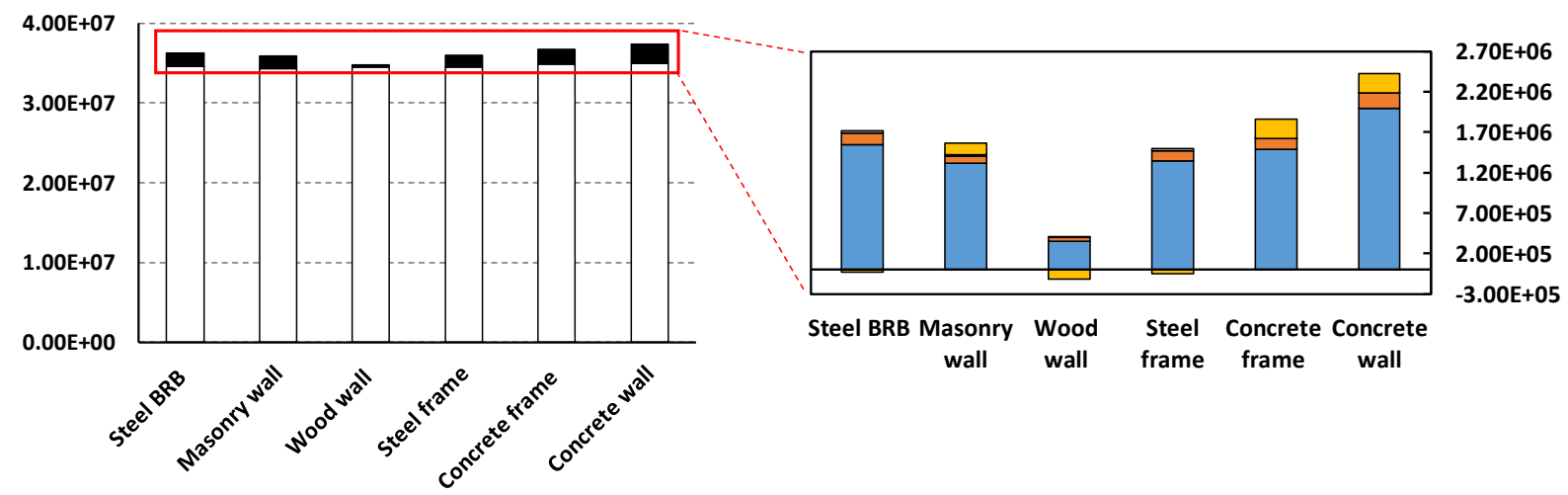

(a) Global Warming Potential [kg $\mathrm{Co}_{2}$ eq]

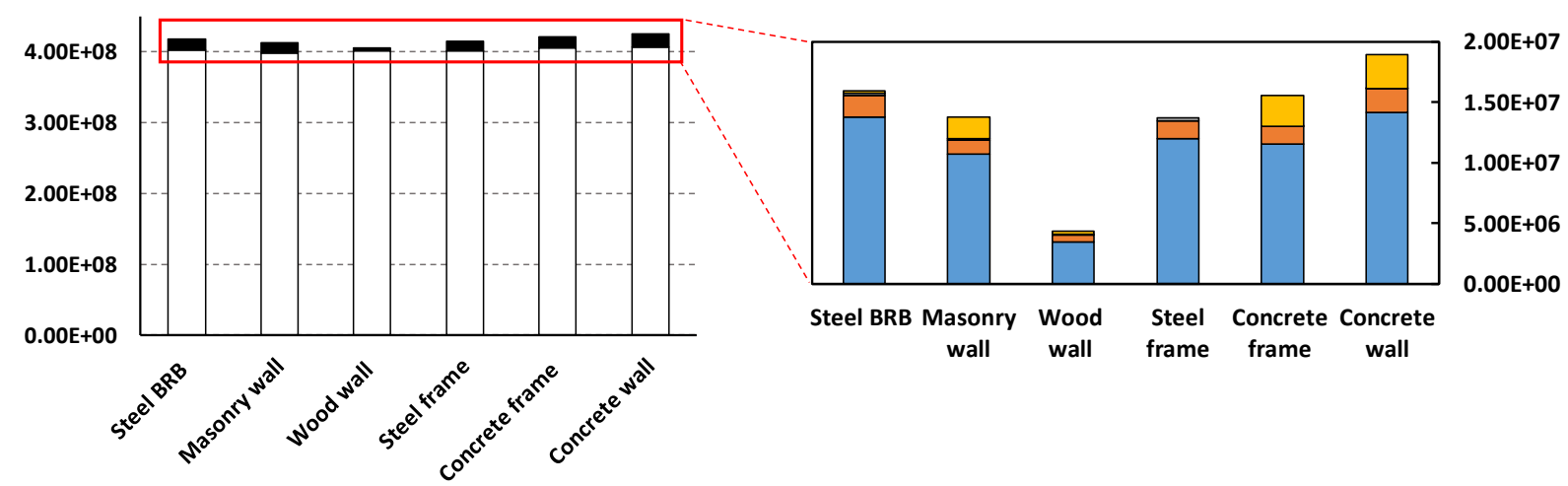

(b) Fossil Fuel Consumption [MJ]

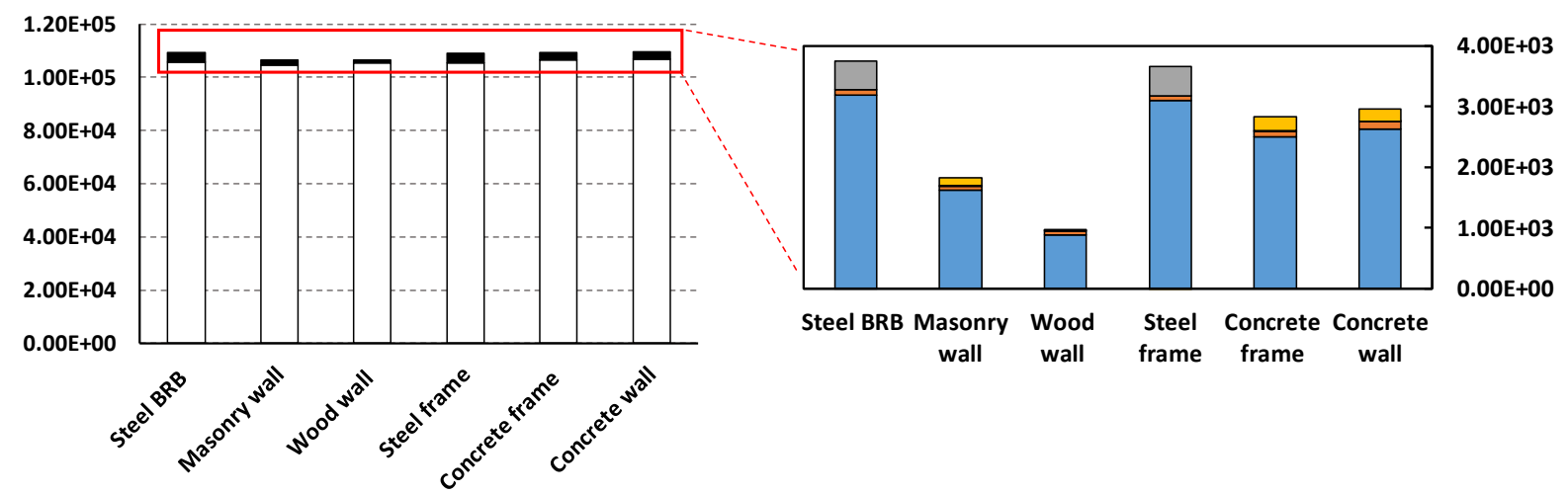

(c) HH Particulate emission [kg PM2.5 eq]

\section{$\square$ Operational $\square$ Embodied $\square$ Production $\square$ Construction $\square$ Maintenance $\square$ End of Life}

Fig. 5: Comparison of life cycle stages contribution to impacts: (left) Operational and embodied (right) Decomposing embodied impacts to production, construction, maintenance, and end-of-life stage' contribution. 
and up to $90 \%$ of total emission for highly energy-efficient buildings [76]. Therefore, this section investigates embodied impacts, which are governed by subsystem selection.

Figure 6 investigates the role of different assemblies on embodied impacts. Overall, the wood wall building has the lowest embodied impact across all different impact categories. In contrast, concrete wall building has the largest embodied impacts except for HH particulate emission where steel BRB buildings exhibit the highest impact.

Comparing between different structural subsystems, concrete frame building shows the highest impacts for all measures, whereas the wood shear walls show the smallest impacts. For example, wood shear walls' contribution to embodied GWP and fossil fuel consumption are $4 \%$ and $2 \%$ of the concrete frame structure, respectively. Additionally, replacing concrete beams with shear walls resulted in a $45 \%$ reduction in concrete wall embodied GWP comparing to the concrete frame. While steel frame and BRB subsystems show small ozone depletion and eutrophication impacts, they have significant HH particulate emission, GWP, and fossil fuel consumption, albeit lesser than concrete structural systems.

Post-tensioned slabs of concrete wall building show the highest contribution to embodied impacts between different flooring systems, except for HH particulate and fossil fuel consumption where precast hollow-core planks incur a higher environmental burden. Conversely, wood truss with plywood decking provides the best environmental performance. The higher impact of post-tensioned slab in-

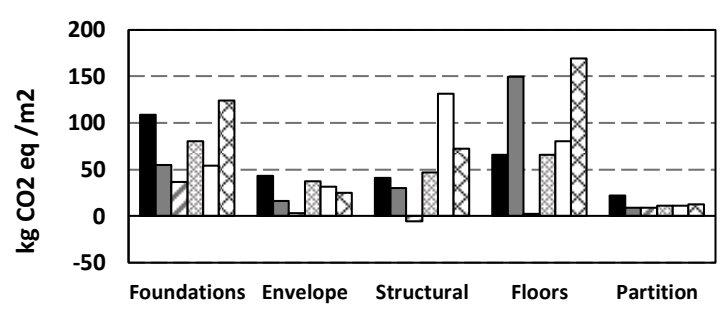

(a) GWP

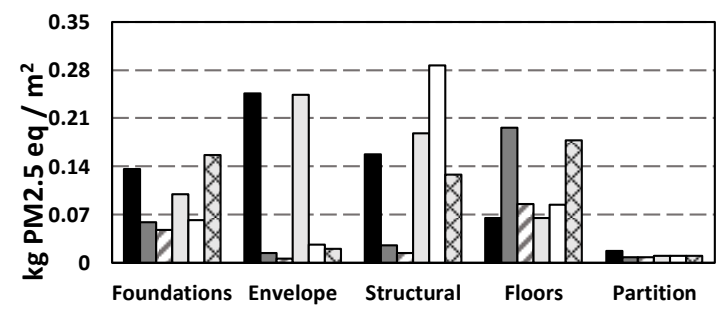

(c) HH Particulate

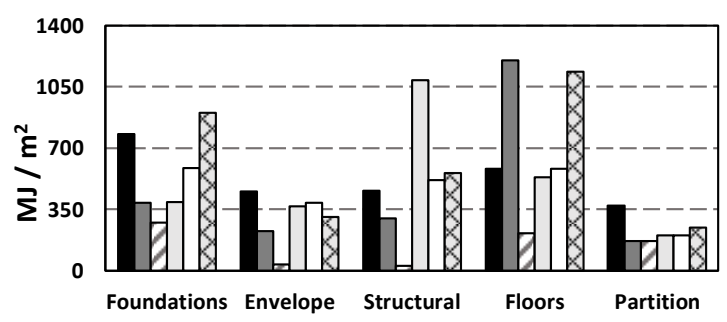

(e) Fossil Fuel Consumption

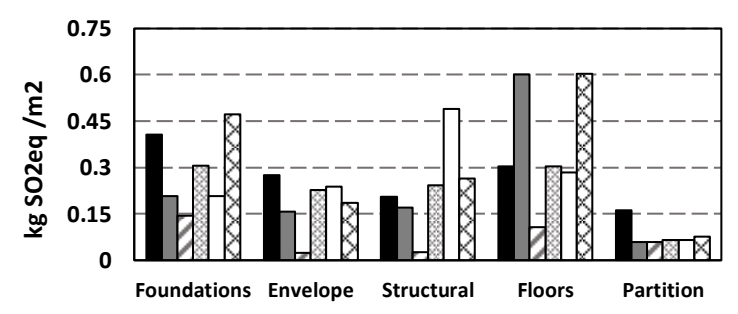

(b) Acidification

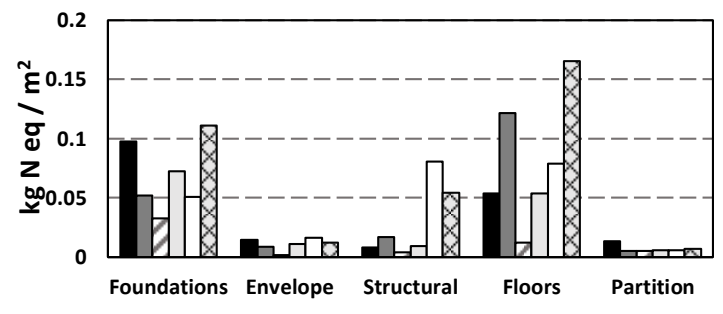

(d) Eutrophication

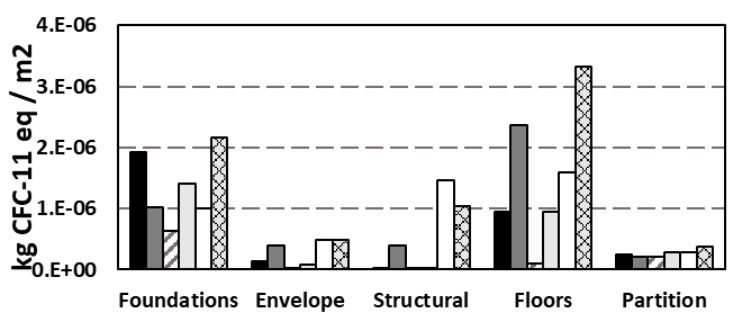

(f) Ozone Depletion

- Steel BRB $\square$ Masonry wall $\square$ Woodwall $\square$ Steel frame $\square$ Concrete frame $\square$ Concrete wall

Fig. 6: Comparison of different subsystems' embodied impacts 
creases concrete wall building embodied impacts to the extent of surpassing concrete frame system. It is common to use post-tensioned slabs in conjunction with column/wall system to replace beam (hence minimizing material use and improving constructability). The results emphasize that the compatibility between floor and structural system (from structural and construction perspectives) could results in systems that, as whole, are not as environmentally-friendly as each constituents subsystem. Here, while wall/column systems has lower impact than frame system, the necessity of post-tensioned slab to compensate for the lack of beams, result in a system with overall higher impact.

Foundation systems of different archetypes use the same material (concrete and steel) where their volume is dictated by the superstructure weight. In this regard, strip foundation of wood wall building and spread foundation of concrete wall buildings have the smallest and largest impacts, respectively. The smaller impact of wood buildings' foundation can be attributed to the superstructure's lighter weight, which led to a smaller (in terms of concrete volume) foundation system. For the envelope system, wood stud walls provide the least embodied impacts, whereas the mixture of the spandrel glass wall and concrete block with brick veneer has the highest impact, particularly for $\mathrm{HH}$ particulate. Lastly, the contribution of partitions is close between different systems since the same plan layout is used in all archetypes. Except for fossil fuel consumption, partitions' contribution to embodied impacts is negligible.

\section{Sensitivity assessment}

In the last section, the contribution of different subsystems to the buildings' life cycle impacts was quantified. In this section, the sensitivity of life cycle impacts to different subsystems will be discussed to determine the most influential design parameters.

\subsection{Impact of the envelope system}

Two important early design parameters impacting envelope selection are envelope material/system and window-to-wall ratio (WWR). To compare the impact of envelope construction, Figure 7 compares four envelope walls alternative for the BRB steel building. The alternatives include spandrel glass wall, steel stud wall, CMU mass wall, and cross-laminated timber (CLT) wall. Details of envelopes constructions are provided in Table 5 . As figure 7 shows, there is no significant difference between buildings' operational energy (coefficient of variation of $2 \%$ ), reinforcing the prior observation that code-conforming envelopes provide the same operational impact. However, CLT and steel stud walls show significantly smaller embodied energy, where they have $68.8 \%$ and $58 \%$ lower embodied energy than the spandrel wall. For embodied GWP, CLT provides a negative value (due to $\mathrm{CO} 2$ absorption during the wood material production process). Lastly, for total GWP and energy (both embodied and operational) CLT wall provides the least impacts, which is $58.5 \%$ of the wall with the highest total impact.

Figure 8 compares the impact of different window-to-wall ratios (WWRs) on total GWP and operational energy use of archetype buildings. It should be noted that the original envelope subsystems

Table 4: Envelop modeling sensitivity details

\begin{tabular}{ll}
\hline Envelope & Description [constituent layers from outside to inside] \\
\hline Spandrel wall & Spandrel glass, Expanded polystyrene insulation $(50 \mathrm{~mm})$, Gypsum board \\
Steel stud wall & $\begin{array}{l}\text { Regular lime stucco, Expanded polystyrene insulation }(75 \mathrm{~mm}), \text { Gypsum board (12 } \\
\text { mm }) \text {, Fiber Glass }(152 \mathrm{~mm}) \text {, vapour barrier, Gypsum board }\end{array}$ \\
CMU wall & PE membrane, Portland Stucco, Concrete brick, Fiber glass (50 mm), Air barrier, \\
& Gypsum board $(12.5 \mathrm{~mm})$ \\
CLT wall & Composite wood siding $(10.5 \mathrm{~mm})$, Air barrier, Rockwool comfortboard $80(50 \mathrm{~mm})$, \\
& Stora Enso CLT, Air barrier, Gypsum board \\
\hline
\end{tabular}




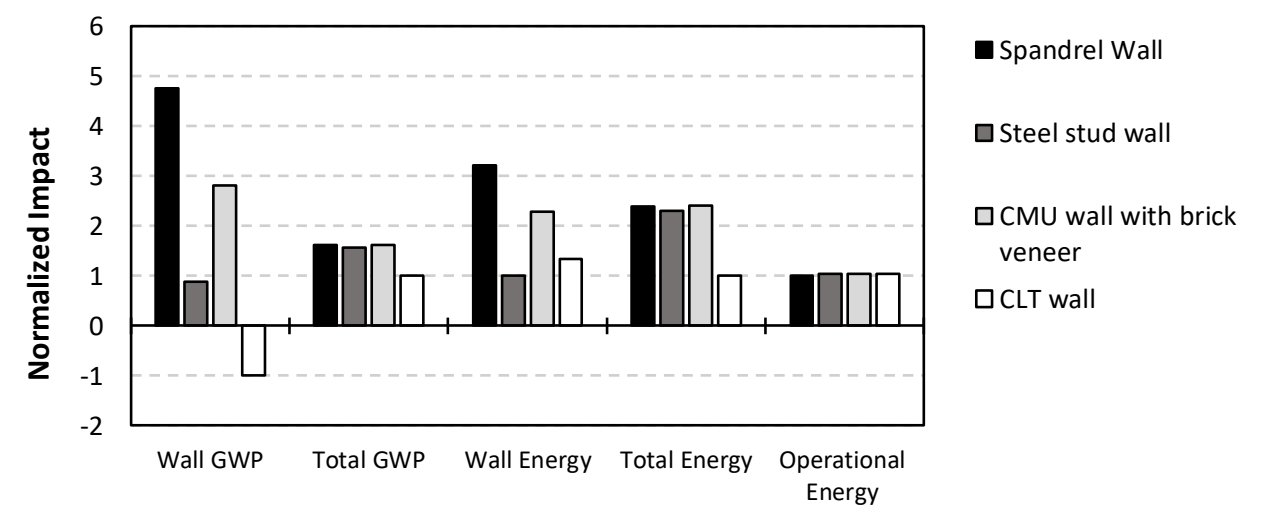

Fig. 7: Comparison of four different envelope construction
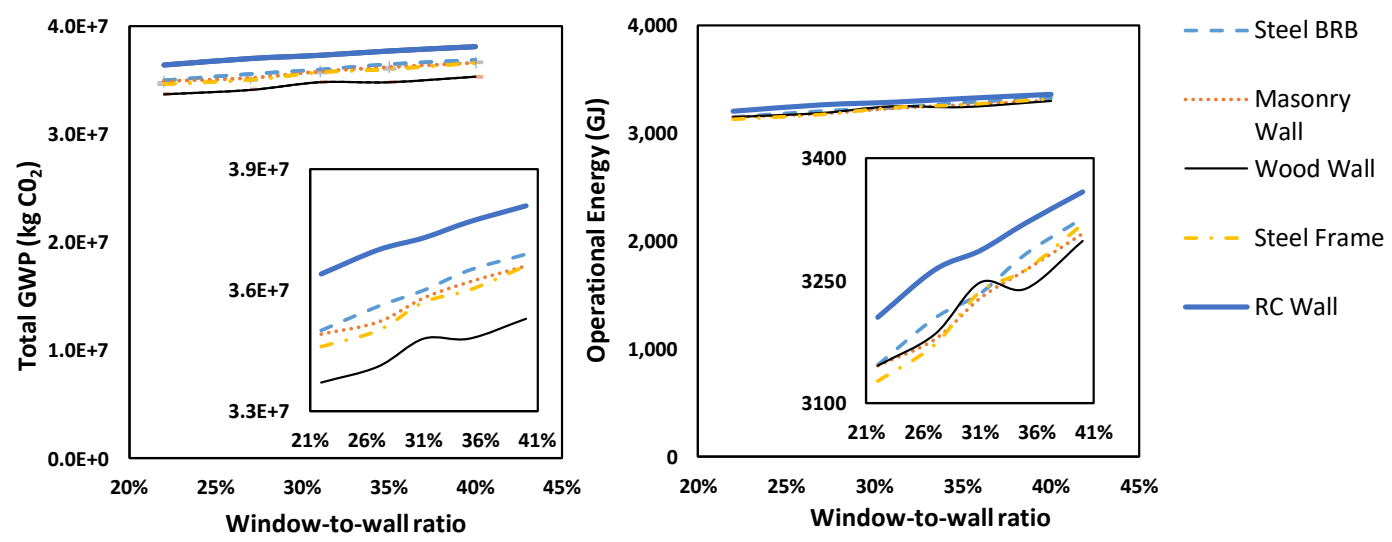

Fig. 8: Comparison of total GWP and operational energy sensitivity to window-to-wall ratio

are modified based on new WWR values, and RC Frame buildings are not considered as they have identical envelope system as the masonry building. For the range of considered window-to-wall ratios (i.e. $22 \%$ to $40 \%$ ), all archetypes show up to a $5-6 \%$ increase in operational energy, where steel frame shows the steepest slope and wood wall shows the most gentle slope, respectively. Similarly, higher WWR results in up to $5-6 \%$ total GWP, where each $1 \%$ increase in WWR yields on average 9900 Ton CO2 in 50 years for archetype buildings. Lastly, while WWR and envelope assembly selection (except for CLT) have similar impacts on total GWP and energy (less than $7 \%$ change), using CLT envelope could notably reduce environmental impacts (e.g. $38 \%$ reduction in total GWP).

\subsection{Impacts of foundation, structural and floor system}

Figure 9 shows the sensitivity of three embodied impacts (GWP, HH emission, and fossil fuel consumption) to the material quantity of different subsystems. The embodied impacts are normalized to the original archetype's values, and two levels of $15 \%$ increase and decrease in material quantity are considered. The selected $15 \%$ threshold follows a practice-based rule of thumb that a typical design is within $15 \%$ of the acceptable range in terms of material quantity. Since alternative designs for each particular archetype building were not available, several assumptions are made: (1) The interaction between different subsystems are ignored, e.g. a $15 \%$ increase in the structural system would have otherwise required a new foundation system to accommodate superstructure new weight (2); It is assumed that all constituent materials in each subsystem will be uniformly scaled, which is an overestimation e.g. a $15 \%$ increase in the foundation is achieved by simultaneously increasing original design values of both steel reinforcement and concrete, whereas smaller reinforcement 


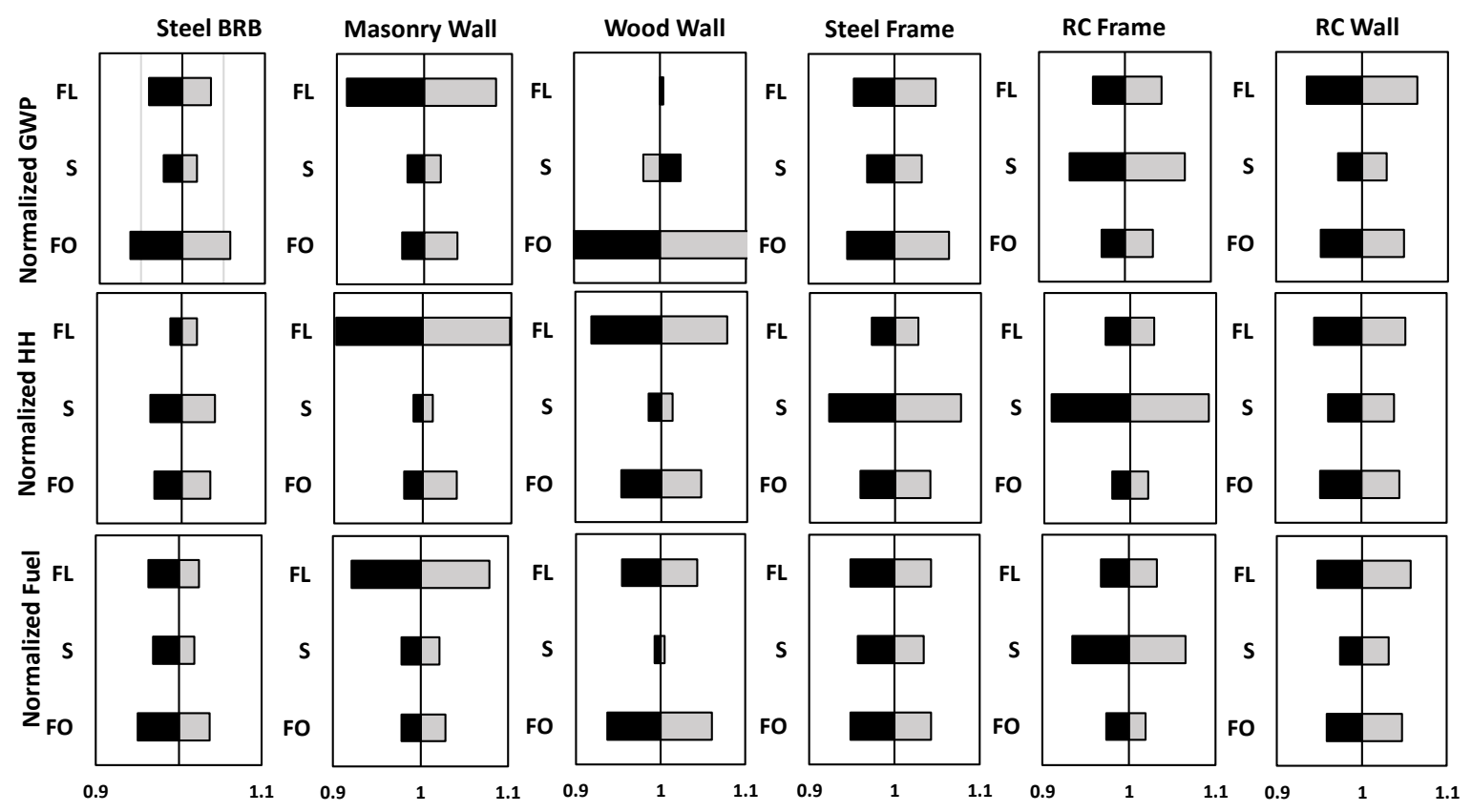

Fig. 9: Comparison of subsystems' contribution to embodied impacts

might be needed. Therefore, the results of this sensitivity should be understood in the context of a comparative measurement of system environmental output.

Figure 9 suggests that except for RC Frame building, foundation and flooring systems pose the highest embodied impact, hence should be prioritized to improve the building's sustainability. Figure 9 also indicates that the effect of different subsystems is not strictly linear in all cases (i.e. symmetry does not always hold for all subsystem and building types). For both steel buildings (BRB and frame), reducing the foundation system's volume is more effective than other systems for all embodied impacts except for HH particulate. For all wall-typed structural systems (i.e. masonry, wood, and RC buildings), the walls induce significantly lower contribution, where their floor systems have the highest importance, particularly for masonry building. For example, there is no meaningful difference between $15 \%$ higher or lower volume of walls for GWP and HH particulate impacts of the masonry wall building. This can also be attributed to the special "masonry" cement in masonry CMU blocks, which contains relatively lower values of clinker, a key agent in the emission of carbon dioxide. Similarly, the environmental performance of the wood building is invariant to the structural system (i.e. wood walls) for acidification, HH particulate, and fossil fuel consumption and is negatively related to GWP. Furthermore, the only case where the structural system of the archetype benefits from early design optimization belongs to the $\mathrm{RC}$ frame building, as concrete moment-resisting frames dominate all sensitivity results.

Figure 10 constructs upper and lower bounds on archetype buildings to determine whether optimizing building design could offset choosing a lesser environmentally-friendly subsystem at early design. The bounds are determined based on individual subsystem bounds from Figure 9. The results suggest that material/design optimization cannot compensate for a sub-optimum decision at the early design phase in all cases. Figure 10 shows that if the designer does not consider the wood wall as an alternative, there is no pathway to similar GWP performance using other alternatives. Additionally, Figure 10 demonstrates that even for cases where optimization might introduce similar environmental performance, it is more feasible to consider optimizing alternatives with higher overlapping of performance bounds. For example, it is easier for the designer to optimize masonry building (less material reduction is needed) than $\mathrm{RC}$ wall building to achieve a similar $\mathrm{HH}$ emission level as the steel frame. 

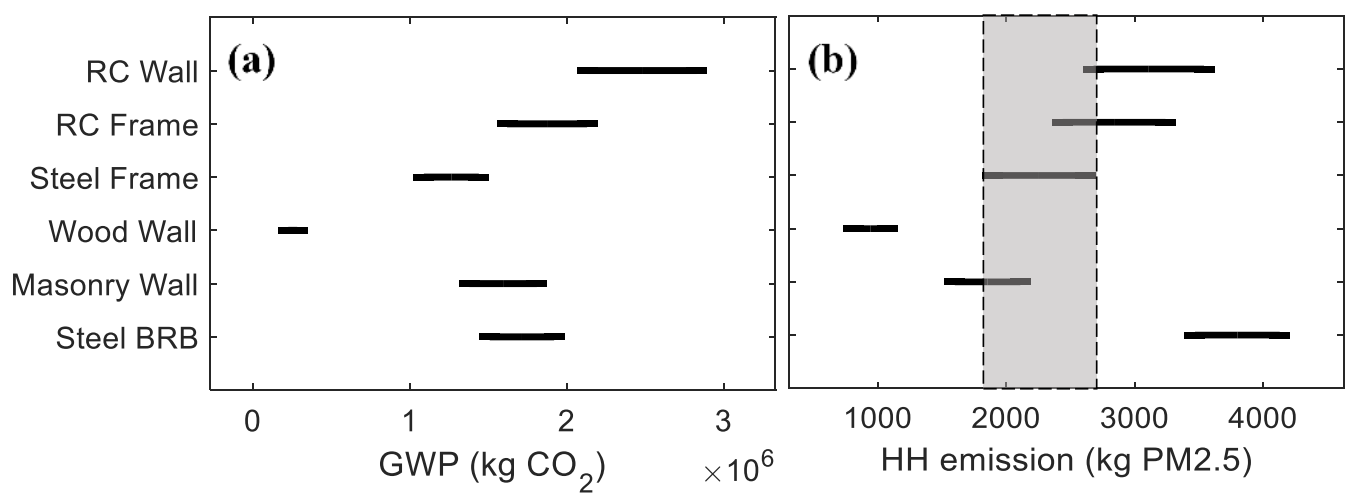

Fig. 10: Total embodied impact bounds for different systems, (a) GWP (b) HH. The shaded area in plot (b) demonstrates how performance bounds of $\mathrm{RC}$ wall, $\mathrm{RC}$ frame, steel frame and masonry wall overlap for $\mathrm{HH}$ emission level.

\section{Statistical analysis of office LCA data}

This section investigates how LCA data can be leveraged to deduce subsystem selection guidance at early design. First, a meta-analysis is performed on available whole-building LCA data from the literature and compared to this study's results. Then both data sources (i.e. literature and this study) are aggregated to compile an environmental performance inventory and statistical methods are applied to identify buildings with higher environmental performance.

\subsection{LCA data compilation \& comparison}

The building LCA data is extracted from published results (shown in Table 1) and post-processed [36] to represent embodied impacts of building with similar assemblies as shown in Figure 11. Only GWP and embodied energy impacts are selected as they are the most prevalent reported impacts in the literature. The comparison is made for concrete and steel buildings, since not enough studies are available for wood and masonry buildings. Additionally, the study by Wu et al. [51] is deemed an outlier and excluded from the data because the reported values were more than three standard deviations from other values, due to the study's location (i.e., China) intensive production processes. Figure 11 shows that while the median embodied GWP of concrete buildings is higher than steel ones, the steel GWP data has a higher variation. Comparing embodied energy, both building groups have similar median values, however, concrete buildings have higher variation than steel ones. Nevertheless, for both impacts and building types, the results of this study (shown as dots in Figure 11) are similar to the lower range literature.
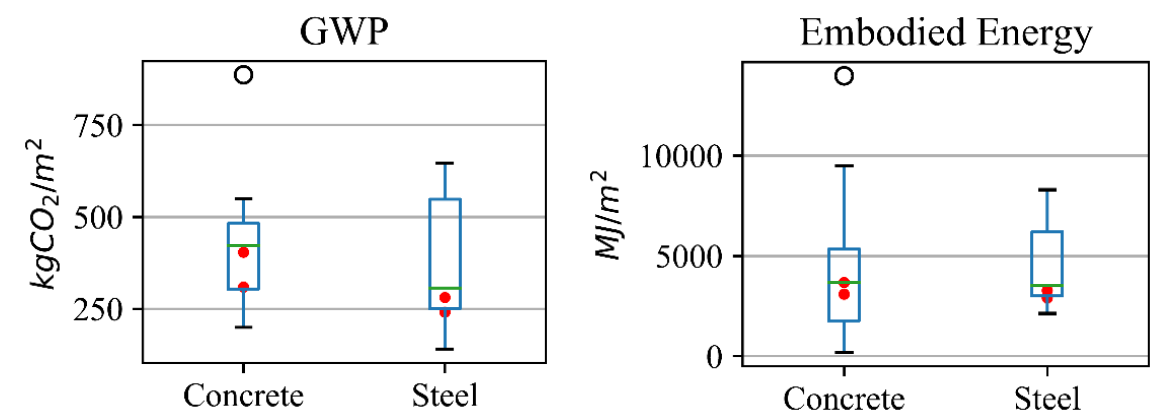

Fig. 11: Comparison of embodied LCA literature data (boxplots) and this study's results (red dots) 


\subsection{Application of LCA inventory for early design}

An unpaired (i.e. independent) t-test is performed on the compiled LCA inventory to compare steel and concrete alternatives from GWP and embodied performance perspective. The independent t-test measures whether there is a statistically significant difference between the mean of different data groups that can be attributed to the population at which samples are extracted [77, 78. Here the t-test hypothesis is taken as whether the average embodied impacts for concrete and steel buildings groups are equal. Due to the limited available inventory, performance assessments are not filtered to distinguish between different types of concrete and steel buildings (e.g. both buildings with concrete frames and walls are grouped under the same "concrete" category).

As Table 6 shows t-tests have high p-values, implying that the mean of steel and concrete building cannot be distinguished for both impacts. Moreover, the $95 \%$ confidence intervals on means' difference cover positive and negative values, suggesting that each building category might have a higher or lower impact. With the addition of the results of this study, the t-test still shows no significant result, however, the new data reduces the confidence interval of the mean difference.

Since the sample size is quite small, the inability to reject the null hypothesis might be due to small statistical power. Power analysis determines the probability of detecting a true effect (i.e. rejecting the null hypothesis) when it exists (i.e. the null hypothesis is actually false). In a mathematical sense, power is defined as the complementary probability of failure to reject a false null hypothesis (type II error). Therefore, a power analysis is performed to determine the adequate sample size to reject the null hypothesis with a power of 0.8 . The results showed that 232 samples are required for each concrete and steel buildings (464 in total) for embodied GWP, whereas a total sample size of 6032 buildings is required for embodied energy. Compared to the current state of 11 buildings, considerable efforts are needed to compile LCA inventory that can facilitate rigorous statistical inferences. As two concluding remarks, the independent t-test assumes that each data group follows a normal distribution, and requires at least 5 samples in each group to allow for approximating t-statistic with a t-distribution. While it was assumed that the embodied impacts follow normal distribution for both building types, such assumption needs to be revisited. Second, the sample size

Table 5: Statistical analysis of published embodied LCA data

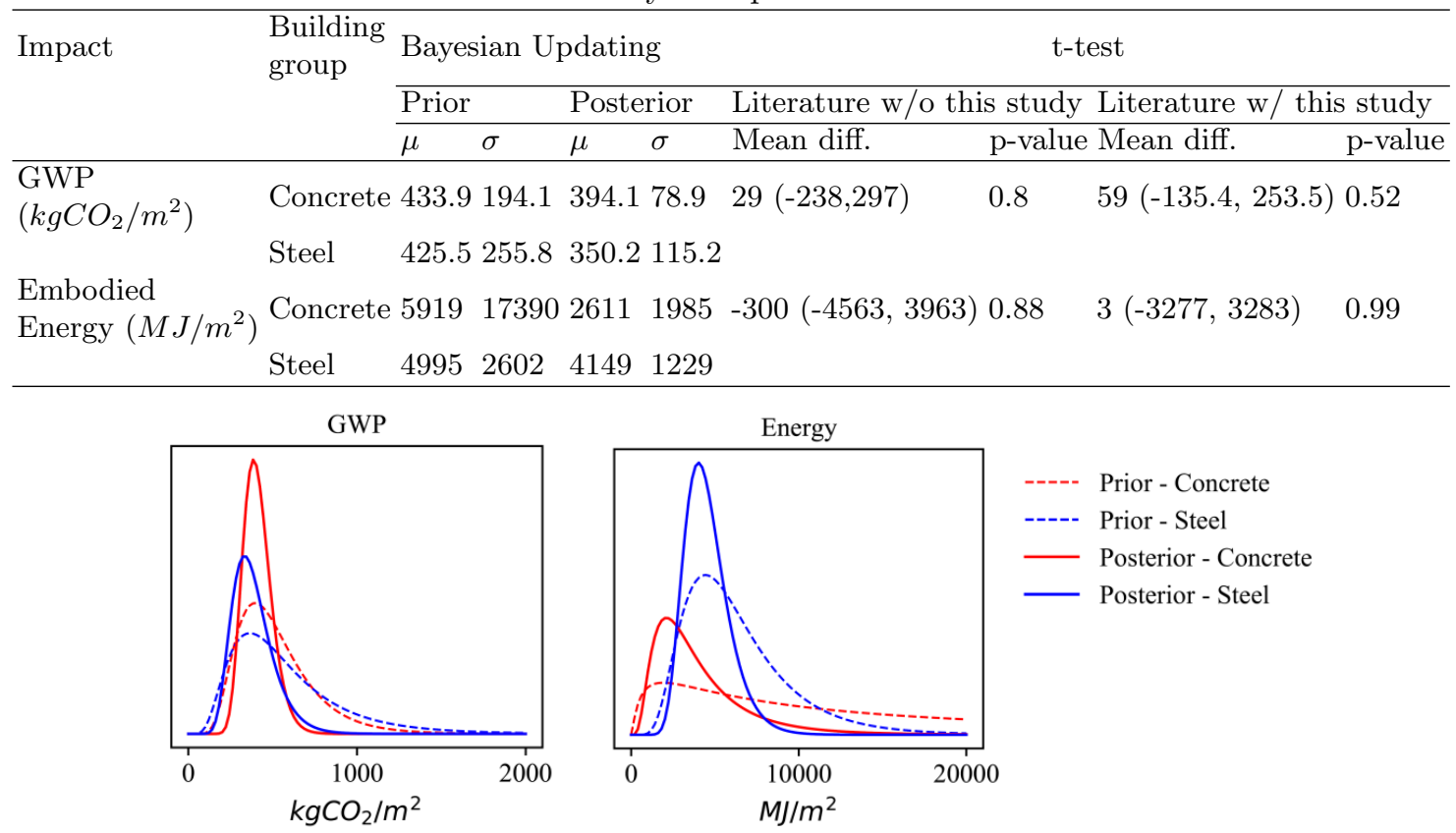

Fig. 12: Comparison of embodied LCA literature data (boxplots) and this study's results (red dots) 
for a given power also depends on the effect size, i.e. the magnitude of difference between groups. For a large effect size, smaller samples are needed to achieve the same power, hence a smaller sample might be adequate if different buildings and design variations are separated when more data becomes available.

\subsection{Bayesian Updating of LCA data}

The previous section implies that a large LCA database is needed to infer early design guidance through classical statistical methods such as hypothesis testing. Bayesian analysis provides a viable solution to reduce the epistemic uncertainties due to limited available LCA data. In this regard, Bayesian analysis characterizes the uncertainties in the model parameters (e.g. distribution parameters of embodied impacts for each alternative group), and updates the existing knowledge about it (i.e. prior distribution) when new assessment data is obtained to yield an updated posterior distribution [79.

To demonstrate Bayesian analysis application, first, it is assumed that each impact can be described using a lognormal distribution (i.e., $L N(\mu, \sigma)$ ) where the and are model parameters that follow normal and half-normal distributions, respectively. The expected values of these model parameters are determined from the reported values of the literature. A posterior distribution is then obtained for each building group using a Markov Chain Monte Carlo method based on new data from this study [80, 81]. 120000 samples from the posterior distribution are generated for each building type's impact and plotted against the original distribution from the literature data in Figure 12. Figure 12 (and Table 6) suggest that while the average values of the two groups change, the impact of new data on variance is more significant and the variance of all distributions is reduced. Intuitively, the higher confidence in the predicted expected values (smaller variation) could be translated into better initial values for early design decision making. Moreover, the results from this study increased the difference between concrete and steel buildings distribution for GWP, while keeping the difference almost the same for embodied energy.

\section{Conclusion}

\subsection{Summary}

This study has two objectives: (1) to provide insight into the impact of subsystem selection (i.e. intersystem variability) on the life cycle impacts of mid-rise office buildings for early design exploration, and (2) to investigate the preliminary idea of compiling LCA inventories (by aggregating literature and new simulation) that can support data-driven early design. To this end, six professionallydesigned archetype buildings (steel BRB, masonry wall, wood wall, steel frame, concrete frame, and concrete wall buildings) were analyzed using a process-based life cycle assessment method. These building meet relevant construction, geotechnical, and structural requirements, hence represent the expected life cycle impacts of real-world design for commercial buildings. The operational energy of all buildings was also explicitly modeled, where a range of code-compliant envelope systems was selected for the given climate. Additionally, each building's constituent subsystems (i.e. floor, structural, and foundation and envelope systems) are selected based on internal compatibility to consider synergies between different subsystems that shape the final environmental performance, e.g. using a post-tensioned floor system with concrete wall structural system. Lastly, different sensitivity assessments on operational and embodied environmental impacts were performed, and statistical approaches were implemented to infer subsystem selection guidance. The followings summarize the main findings of this study:

1. Wood wall building shows the lowest embodied impacts across all measures, whereas concrete wall building has the highest embodied impacts except for $\mathrm{HH}$ emission. 
2. Except for fossil fuel consumption and HH emission, steel buildings (i.e., steel frame and braced systems) tend to outperform concrete alternatives (i.e., concrete frame and wall building).

3. Among four different considered envelope systems (i.e., spandrel, steel stud, CMU and CLT), CLT envelope led to the lowest total GWP and energy impacts, indicating $38 \%$ and $58 \%$ smaller total GWP and energy relative to the building with the highest impact.

4. Constructing environmental embodied impacts bounds based on subsystem's material variability, the results suggest that design optimization could not always offset excluding a possible environmentally-friendly alternative at early design.

5. Current LCA literature suggests that concrete buildings have higher embodied GWP than steel buildings, whereas both building categories have the same embodied energy. However, the independent t-test does not show a statistically significant difference between concrete and steel buildings' embodied GWP and energy.

6. Bayesian analysis of combined LCA inventory suggest that steel building could have lower embodied GWP but higher embodied energy than concrete buildings.

Other notable findings of this study are as follows:

7. Operational (use) stage dominates considered environmental impacts for all archetype buildings, whereas the production stage governs embodied impacts.

8. No single building subsystem (e.g. floor, structural) is influential across different embodied environmental impacts for all archetypes.

9. For steel buildings, the maintenance stage was deemed unimportant for embodied GWP and fossil fuel consumption impacts, whereas it has a tangible contribution to embodied $\mathrm{HH}$ particulate emission.

10. Except for fossil fuel consumption, partition walls' contribution to embodied impacts were negligible relative to other building assemblies.

11. Code-compliant envelope systems with different construction sets yield similar operational energy demand with a $2 \%$ coefficient of variation for the climate under study.

The results suggest that open whole building LCA assessment data (performed using consistent assumptions and analysis choices) can be utilized as environmental performance inventory to deduce early design guidance through statistical inference. In addition, such data can be seamlessly integrated with other assessment type (e.g. life cycle cost) to create multi-dimensional performance inventories for holistic data-driven design frameworks. For example, the LCA model of concrete frame archetype from this study was used as the basis for the environmental performance of an inventory of commercial concrete buildings under earthquake hazard 82. Similar extensions for holistic evaluation of other building types (e.g. steel frames) are feasible. Furthermore, the data from the studied subsystems can be combined with other subsystems to obtain life cycle impacts of novel solutions, such as steel building with dampers.

\subsection{Future direction implications for early design}

The results show that operational GWP is on average thirty-seven times larger than embodied GWP due to aggregated contribution of production, construction, maintenance, and end-of-life. From an early design perspective, all the selected envelope systems had similar operational energy, and consequently environmental performance, except for the CLT envelope which offered a tangible improvement for environmental performance. Moreover, the early decision on the window-to-wall ratio did not significantly impact the operational phase (i.e. around $5-6 \%$ change). However, this slight change in operational impacts is almost equal to the embodied contribution from all other subsystems (due to conspicuously larger contribution of use phase). Although the enormous gap between embodied and operational impacts urges the necessity of sustainable energy plan (such as the application of modern smart power utilities and passive energy systems), an environmentally 
conscientious building early design is still critical. This is because while building use impacts can be mitigated in future, the construction of fossil-fuel intensive buildings generates embodied impacts that will contribute to carbon lock-in effects.

Moving towards energy-efficient offices, the results suggest that the initial embodied environmental performance of a design is mostly influenced by floor and foundation systems, due to the large volume of environmentally-critical materials such as concrete. Nevertheless, the current design practice of foundation and floor systems are mostly driven by other factors than meeting a sustainable construction. Foundations are designed to safely transfer superstructure's loads to the supporting ground and their sizing and selection are made based on soil condition, possible lateral loads (e.g. wind, earthquake), building weight, footprint ratio, and flooding zone. Floor systems are selected and sized to maintain serviceability under expected loads and span length, while accommodating mechanical electrical and plumbing systems. Therefore, introducing sustainability criteria in floor and foundation selection/design either by reducing material usage or new innovative systems with low embodied burden, could be the future direction to achieve greener office buildings.

The major obstacle for data-driven early design is the unavailability of information on design uncertainties. While anecdotal (i.e. expert opinion) and rules-of-thumb do exist, no major effort has been directed to quantify building design (e.g. structural, foundation) variability for a given site and topology. As illustrated in this study, the input uncertainties can be readily mapped to performance bounds for early design decisions. The preliminary efforts of this study suggest that it is critical to include all possible alternatives at the divergent phase of early design, as further optimization in the convergent phase might not lead to the best performing alternative. Furthermore, it should be noted that the presented archetypal buildings only covered a limited combination of different subsystems, whereas considering a larger number of flooring and envelope system could improve the representativeness, and consequently the inferred conclusions on the best combination of subsystems.

Performance inventories that contain information on design taxonomy and building performance across multiple domains could offer a viable tool to facilitate ML/statistical LCA methods. This study examined the idea of combining limited literature data with performed LCA to compile a proof-of-concept LCA inventory. While building performance inventories have been proposed and used in other fields such as earthquake engineering 83, whole building LCA has not yet been prevalent or readily accessible, preventing the application of rigorous statistical and ML methods. A power analysis to determine the required sample size showed that around 400 additional LCAs are needed to answer whether there is a statistically significant difference between embodied GWP of concrete and steel buildings, emphasizing the necessity of performing and documenting similar LCA studies for different building taxonomies. Perhaps a more impactful future direction for building LCAs is to focus on constructing such open databases, rather than employing MLs for specific projects that cannot be generalized beyond the project's specific details.

\section{Acknowledgment}

This research is supported by the U.S. National Science Foundation, Division of Civil, Mechanical, and Material Innovation, through Resilient Sustainable Buildings Award 1455466. Natalia Zhukova and Jeonghyun Lee are thanked for their contribution to the initial LCA and energy analysis of two buildings. 


\section{APPENDIX 1: Envelope systems taxonomy and description}

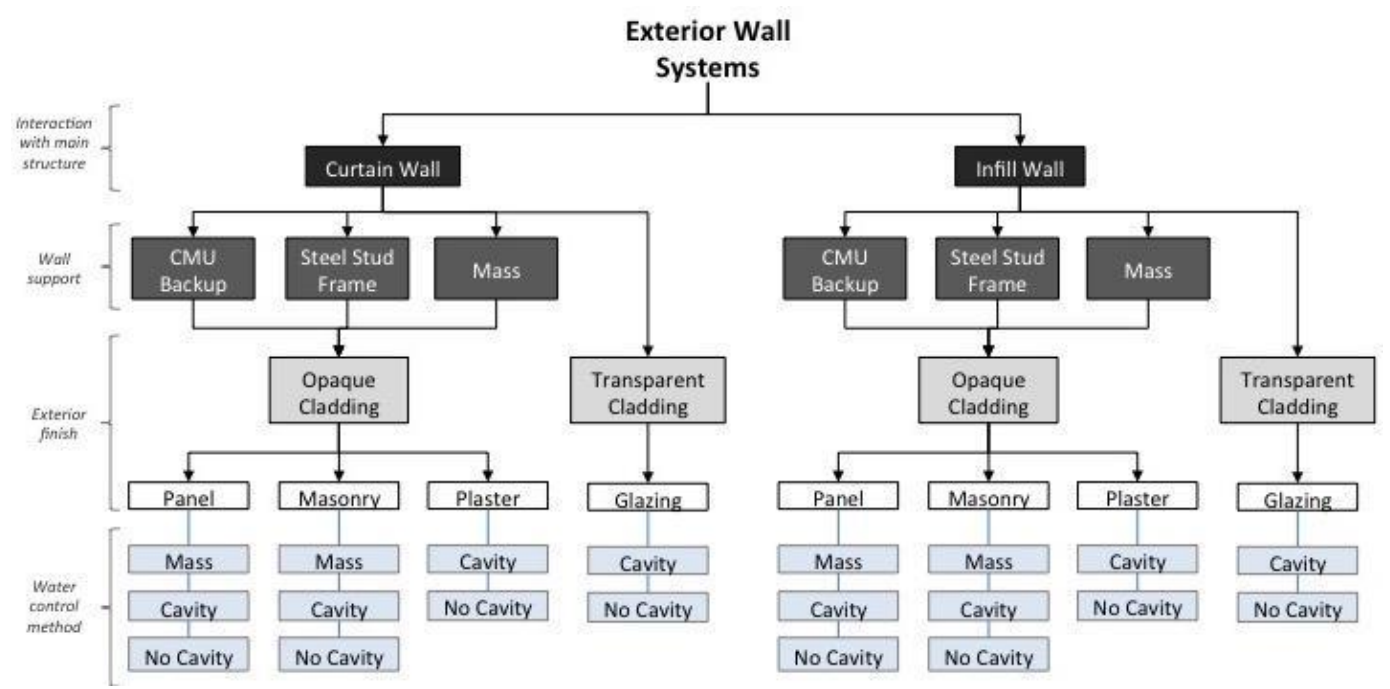

\section{Appendix 2. Material life cycle inventories}

\section{Ready Mix Concrete}

The Athena LCI database covers 150 benchmark and alternative mixes which are linked to cement profiles based on location. The concrete mix LCIs are derived from the industry wide benchmark of the "National Ready Mixed Concrete Association (NRMCA)" [84. The NRMCA data for readymix concrete uses a representative sample of 469 member plants located in the US and Canada. The LCI study includes raw material supply, transportation, and manufacturing of the concrete mix. Raw material supply includes the extraction and handling of raw materials, cement, supplementary materials, aggregate, water, and admixtures. Transportation is measured from supplier to the gate of the concrete producer, and manufacturing includes water and the energy to batch-mix and concrete distribution. In addition, the following processes are excluded from their LCI: transportation to the construction site, on-site construction including forms and formwork, placing and curing and reinforcement, the production of building capital goods and infrastructure, concrete production equipment, concrete delivery vehicles, laboratory equipment, personnel-related activities, company management, and sales activities.

\section{Steel}

ATHENA uses the "World Steel Association (WSA)" global Life Cycle Impact (LCI) dataset for steel, which covers 17 types of steel products ranging from hot-rolled coil to rebar, wire rod, and engineering steel 85 . WSA LCI consists of "non-mass" inputs (electricity, compressed air, and water) and $98 \%$ of material inputs (raw materials, energy, and consumables). The LCI includes raw material production and transportation, co-products, the steelmaking process, recovery processes, wastewater treatment, ancillary processes, and internal transportation during the steelmaking process up to the finished steel products. The majority of the upstream data was obtained from $\mathrm{GaBi}$, a commercial database, and when possible was taken from other industry associations. The manufacturing information comes from 115 sites representative of most areas of the world and a range of operating configurations and produces $24 \%$ of global crude steel production [85. However, Athena has regionalized the data to reflect North America steel production technologies and market recovery rates. The technology 
processes used are blast furnace/ basic oxygen furnace (BOF) and electric arc furnace (EAC). Capital goods, RD, business travel, repair and maintenance, legal services, marketing, and management operations are not included [86].

\section{Concrete masonry unit (CMU) blocks}

ATHENA data for CMU blocks reflects Portland Cement Association design mixes and average cement content for the U.S. The Portland Cement Association provides an environmental product declaration (EDP) for Masonry Cements as defined by ASTM C219. Based on their EDP, the U.S. industry average masonry is $57.5 \%$ clinker by weight, with smaller portions of un-calcined limestone (36.1\%), gypsum (4.85\%), and dust (1.05\%). These values represent a weighted average of masonry cement produced across all U.S. plants. The data reflects the equipment, processes, and market conditions of cement produced in the U.S. in 2014. Their LCI includes extraction and processing of raw materials, transportation of materials from source to plant, consumption of energy and water required to produce cement, emissions and wastes generated from cement production, transportation of wastes, and end-of-life wastes generated during cement production, whereas equipment and infrastructure, and personnel-related activities are excluded.

The clinker production technology profile reflects the same values used for Portland cement. The primary difference between general Portland cement and masonry cement is the quantity of clinker in its composition; While Portland Cement contains roughly $92.2 \%$ clinker by weight, Masonry Cements contain an average of only $57.5 \%$ clinker by weight. This ultimately affects the environmental impact of each material. For example, Portland Cement has a 100-year global warming potential value of $1040 \mathrm{~kg} \mathrm{CO}$-eq. Per metric tonne, while the value for masonry cement is $692 \mathrm{~kg} \mathrm{CO}_{2}$-eq. Per metric tonne. 


\section{Appendix 3. Bill of Material}

Figure A1 shows the bill of materials for all considered archetypes. Overall, cast-in-place concrete is the most used material, except for the masonry building where it is the second most used one. It is interesting to note that steel sections and reinforcements only account for $3 \%$ and $6 \%$ of BRB and steel frame buildings' weight, respectively. Concrete block, brick, gypsum boards, and rebar are other largely used materials, although their quantity is significantly lower than concrete and varies between different archetypes

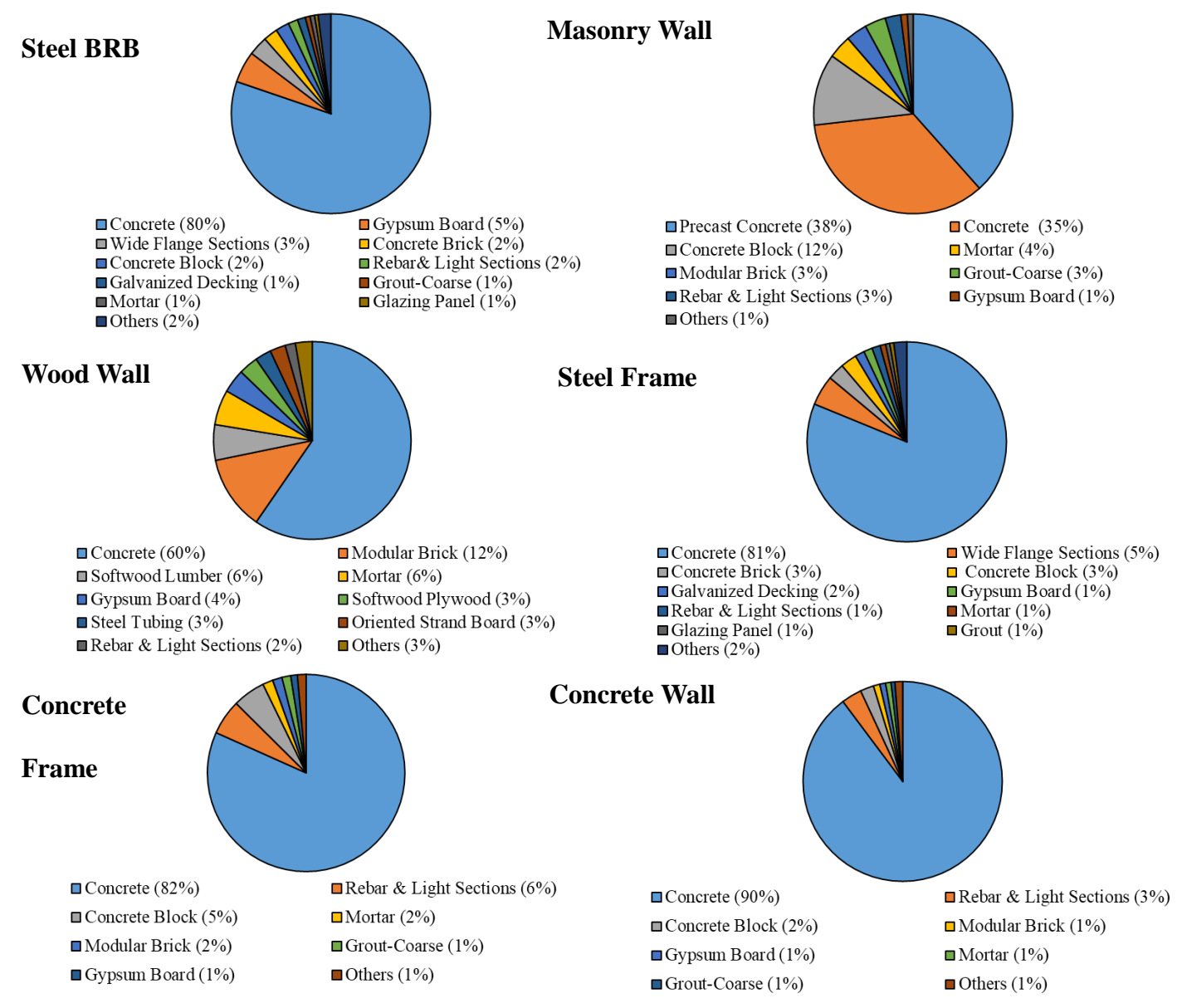

Fig A1: Bill of material 


\section{Bibliography}

[1] John Elkington. Enter the triple bottom line. 2004. ISBN 9781849773348. https://doi.org/10.4324/9781849773348.

[2] Neftali Torres. Study of sustainability opportunities during construction, 2014.

[3] Alexander Passer, Thomas Lützkendorf, Habert Guillaume, Kromp-Kolb Helga, Michael Monsberger, Michael Eder, and Barbara Truger. Sustainable built environment: transition towards a net zero carbon built environment. The International Journal of Life Cycle Assessment, 25 (6):1160-1167, 2020.

[4] Peeraya Inyim, Joseph Rivera, and Yimin Zhu. Integration of Building Information Modeling and Economic and Environmental Impact Analysis to Support Sustainable Building Design. Journal of Management in Engineering, 2015. ISSN 0742-597X. https://doi.org/10.1061/(asce)me.1943-5479.0000308.

[5] M. M. Matar, M. E. Georgy, and A. M. Abou-Zeid. Developing a BIM-oriented data model to enable sustainable construction in practice. In eWork and eBusiness in Architecture, Engineering and Construction - Proceedings of the European Conference on Product and Process Modelling 2010, 2010. ISBN 9780415605076. https://doi.org/10.1201/b10527-15.

[6] Xiaolong Gan, Jian Zuo, Kunhui Ye, Martin Skitmore, and Bo Xiong. Why sustainable construction? Why not? An owner's perspective. Habitat International, 2015. ISSN 01973975. https://doi.org/10.1016/j.habitatint.2015.01.005.

[7] C. K. Chau, T. M. Leung, and W. Y. Ng. A review on life cycle assessment, life cycle energy assessment and life cycle carbon emissions assessment on buildings, 2015. ISSN 03062619.

[8] Maureen A. Olinzock, Amy E. Landis, Christi L. Saunders, William O. Collinge, Alex K. Jones, Laura A. Schaefer, and Melissa M. Bilec. Life cycle assessment use in the North American building community: summary of findings from a 2011/2012 survey. International Journal of Life Cycle Assessment, 2015. ISSN 16147502. https://doi.org/10.1007/s11367-014-0834-y.

[9] Michael Pitt, Matthew Tucker, Mike Riley, and Jennifer Longden. Towards sustainable construction: Promotion and best practices. Construction Innovation, 2009. ISSN 14770857. https://doi.org/10.1108/14714170910950830

[10] Joyce Cooper, Jim Fava, and Steven Baer. Life cycle assessments of buildings in North America: Demand and supply. Journal of Industrial Ecology, 2008. ISSN 10881980. https://doi.org/10.1111/j.1530-9290.2008.00003.x.

[11] Patrick Hofstetter and Thomas M. Mettier. What Users Want and May Need: Insights from a Survey of Users of a Life-Cycle Tool. Journal of Industrial Ecology, 2003. ISSN 10881980. https://doi.org/10.1162/108819803322564361.

[12] Seoung Wook Whang and Sangyong Kim. Balanced sustainable implementation in the construction industry: The perspective of Korean contractors. Energy and Buildings, 2015. ISSN 03787788. https://doi.org/10.1016/j.enbuild.2015.03.019.

[13] Sonia Valdivia, Jana Gerta Backes, Marzia Traverso, Guido Sonnemann, Stefano Cucurachi, Jeroen B Guinée, Thomas Schaubroeck, Matthias Finkbeiner, Noemie Leroy-Parmentier, Cássia Ugaya, et al. Principles for the application of life cycle sustainability assessment. The International Journal of Life Cycle Assessment, 26(9):1900-1905, 2021.

[14] H. Gervásio, P. Santos, R. Martins, and L. Simões da Silva. A macro-component approach for the assessment of building sustainability in early stages of design. Building and Environment, 2014. ISSN 03601323. https://doi.org/10.1016/j.buildenv.2013.12.015.

[15] Kyle Konis, Alejandro Gamas, and Karen Kensek. Passive performance and building form: An optimization framework for early-stage design support. Solar Energy, 2016. ISSN 0038092X. https://doi.org/10.1016/j.solener.2015.12.020. 
[16] Tsai Chi Kuo, Shana Smith, Gregory C. Smith, and Samuel H. Huang. A predictive product attribute driven eco-design process using depth-first search. Journal of Cleaner Production, 2016. ISSN 09596526. https://doi.org/10.1016/j.jclepro.2015.10.005.

[17] Survey of sustainable building design practices in North America, Europe, and Asia. Journal of Architectural Engineering, 2006. ISSN 10760431. https://doi.org/10.1061/(ASCE)10760431(2006)12:1(33).

[18] J Basbagill, F Flager, Michael D Lepech, and M Fischer. Application of life-cycle assessment to early stage building design for reduced embodied environmental impacts. Building and Environment, 60:81-92, 2013.

[19] Joshua Hester, T. Reed Miller, Jeremy Gregory, and Randolph Kirchain. Actionable insights with less data: guiding early building design decisions with streamlined probabilistic life cycle assessment. International Journal of Life Cycle Assessment, 2018. ISSN 16147502. https://doi.org/10.1007/s11367-017-1431-7.

[20] Michael Budig, Oliver Heckmann, Markus Hudert, Amanda Qi Boon Ng, Zack Xuereb Conti, and Clement Jun Hao Lork. Computational screening-lca tools for early design stages. International Journal of Architectural Computing, page 1478077120947996, 2020.

[21] Srikanth Devanathan, Devarajan Ramanujan, William Z. Bernstein, Fu Zhao, and Karthik Ramani. Integration of sustainability into early design through the function impact matrix. Journal of Mechanical Design, Transactions of the ASME, 2010. ISSN 10500472. https://doi.org/10.1115/1.4001890

[22] Josef Peter Schöggl, Rupert J. Baumgartner, and Dietmar Hofer. Improving sustainability performance in early phases of product design: A checklist for sustainable product development tested in the automotive industry. Journal of Cleaner Production, 2017. ISSN 09596526. https://doi.org/10.1016/j.jclepro.2016.09.195

[23] Elcin Aleixo Calado, Marco Leite, and Arlindo Silva. Integrating life cycle assessment (lca) and life cycle costing (lcc) in the early phases of aircraft structural design: an elevator case study. The International Journal of Life Cycle Assessment, 24(12):2091-2110, 2019.

[24] Randa Ghattas, Jeremy Gregory, T Reed Miller, and Randolph Kirchain. The decision-making process in the design of residential structures. Technical report, 2015.

[25] Tianzhen Hong, Zhe Wang, Xuan Luo, and Wanni Zhang. State-of-the-art on research and applications of machine learning in the building life cycle. Energy and Buildings, 212:109831, 2020.

[26] B. D'Amico, R. J. Myers, J. Sykes, E. Voss, B. Cousins-Jenvey, W. Fawcett, S. Richardson, A. Kermani, and F. Pomponi. Machine Learning for Sustainable Structures: A Call for Data. Structures, 2019. ISSN 23520124. https://doi.org/10.1016/j.istruc.2018.11.013.

[27] Michael Buschka, Julian Bischof, Christina Meier-Dotzler, and Werner Lang. Developing nonresidential building stock archetypes for lci-a german case study of office and administration buildings. The International Journal of Life Cycle Assessment, 26(9):1735-1752, 2021.

[28] Marcella Ruschi Mendes Saade, Geoffrey Guest, and Ben Amor. Comparative whole building LCAs: How far are our expectations from the documented evidence?, 2020. ISSN 03601323.

[29] Shuai Lu, Jingyu Li, and Borong Lin. Reliability analysis of an energy-based form optimization of office buildings under uncertainties in envelope and occupant parameters. Energy and Buildings, 2020. ISSN 03787788. https://doi.org/10.1016/j.enbuild.2019.109707.

[30] Mark Kyeredey Ansah, Xi Chen, Hongxing Yang, Lin Lu, and Patrick TI Lam. An integrated life cycle assessment of different façade systems for a typical residential building in ghana. Sustainable Cities and Society, 53:101974, 2020.

[31] Christof Knoeri, Esther Sanyé-Mengual, and Hans Joerg Althaus. Comparative LCA of recycled and conventional concrete for structural applications. International Journal of Life Cycle Assessment, 2013. ISSN 09483349. https://doi.org/10.1007/s11367-012-0544-2.

[32] Ali Tighnavard Balasbaneh and Willy Sher. Life cycle sustainability assessment analysis of different concrete construction techniques for residential building in malaysia. The International Journal of Life Cycle Assessment, pages 1-18, 2021. 
[33] Joshua L. Sohn, Pradip P. Kalbar, Gary T. Banta, and Morten Birkved. Life-cycle based dynamic assessment of mineral wool insulation in a Danish residential building application. Journal of Cleaner Production, 2017. ISSN 09596526. https://doi.org/10.1016/j.jclepro.2016.10.145.

[34] Noelia Llantoy, Marta Chàfer, and Luisa F Cabeza. A comparative life cycle assessment (lca) of different insulation materials for buildings in the continental mediterranean climate. Energy and Buildings, page 110323, 2020.

[35] Vaclav Hasik, Elizabeth Escott, Roderick Bates, Stephanie Carlisle, Billie Faircloth, and Melissa M. Bilec. Comparative whole-building life cycle assessment of renovation and new construction. Building and Environment, 2019. ISSN 03601323. https://doi.org/10.1016/j.buildenv.2019.106218.

[36] Mohsen Zaker Esteghamati, Houri Sharifnia, Diep Ton, Patricia Asiatco, Georg Reichard, and Madeleine M Flint. Life cycle assessment data \& energy models of archetype commercial buildings located in the central and eastern united states, 2021. URL http://hdl.handle.net/ $10919 / 106494$

[37] Luisa F. Cabeza, Lídia Rincón, Virginia Vilariño, Gabriel Pérez, and Albert Castell. Life cycle assessment (LCA) and life cycle energy analysis (LCEA) of buildings and the building sector: A review, 2014. ISSN 13640321.

[38] Peter Ylmén, Diego Peñaloza, and Kristina Mjörnell. Life Cycle Assessment of an Office Building Based on Site-Specific Data. Energies, 12(13):2588, 2019.

[39] Oscar Ortiz, Francesc Castells, and Guido Sonnemann. Sustainability in the construction industry: A review of recent developments based on LCA, 2009. ISSN 09500618.

[40] Ashraf F Ragheb. Towards Environmental Profiling for Office Buildings Using Life Cycle Assessment (LCA). PhD thesis, 2011.

[41] Mohamad Monkiz Khasreen, Phillip FG Banfill, and Gillian F Menzies. Life-cycle assessment and the environmental impact of buildings: a review. Sustainability, 1(3):674-701, 2009.

[42] I. Sartori and A. G. Hestnes. Energy use in the life cycle of conventional and lowenergy buildings: A review article. Energy and Buildings, 2007. ISSN 03787788. https://doi.org/10.1016/j.enbuild.2006.07.001.

[43] Ann Kristin Petersen and Birger Solberg. Environmental and economic impacts of substitution between wood products and alternative materials: A review of micro-level analyses from Norway and Sweden. Forest Policy and Economics, 2005. ISSN 13899341. https://doi.org/10.1016/S1389-9341(03)00063-7.

[44] Elizabeth Stek, Dave Delong, Terry McDonnell, and Jose Rodriguez. Life cycle assessment using ATHENA@ impact estimator for buildings: A case study. In Structures Congress 2011 - Proceedings of the 2011 Structures Congress, 2011. ISBN 9780784411711. https://doi.org/10.1061/41171(401)42.

[45] Chris Scheuer, Gregory A. Keoleian, and Peter Reppe. Life cycle energy and environmental performance of a new university building: Modeling challenges and design implications. Energy and Buildings, 2003. ISSN 03787788. https://doi.org/10.1016/S0378-7788(03)00066-5.

[46] Angela Acree Guggemos and Arpad Horvath. Comparison of environmental effects of steeland concrete-framed buildings. Journal of Infrastructure Systems, 2005. ISSN 10760342. https://doi.org/10.1061/(ASCE)1076-0342(2005)11:2(93).

[47] Seppo Junnila, Arpad Horvath, and Angela Acree Guggemos. Life-Cycle Assessment of Office Buildings in Europe and the United States. Journal of Infrastructure Systems, 2006. ISSN 1076-0342. https://doi.org/10.1061/(asce)1076-0342(2006)12:1(10).

[48] Oyeshola F. Kofoworola and Shabbir H. Gheewala. Environmental life cycle assessment of a commercial office building in Thailand. International Journal of Life Cycle Assessment, 2008. ISSN 09483349. https://doi.org/10.1007/s11367-008-0012-1.

[49] A Dimoudi and C Tompa. Energy and environmental indicators related to construction of office buildings. Resources, Conservation and Recycling, 53(1-2):86-95, 2008. 
[50] Adam B. Robertson, Frank C. F. Lam, and Raymond J. Cole. A Comparative Cradle-toGate Life Cycle Assessment of Mid-Rise Office Building Construction Alternatives: Laminated Timber or Reinforced Concrete. Buildings, 2012. https://doi.org/10.3390/buildings2030245.

[51] Huijun J. Wu, Zengwei W. Yuan, Ling Zhang, and Jun Bi. Life cycle energy consumption and CO2 emission of an office building in China, 2012. ISSN 16147502.

[52] Carley Feese, Yue Li, and William M. Bulleit. Assessment of Seismic Damage of Buildings and Related Environmental Impacts. Journal of Performance of Constructed Facilities, 2014. ISSN 0887-3828. https://doi.org/10.1061/(asce)cf.1943-5509.0000584.

[53] Y. C. Liu, T. Bligh, and A. Chakrabarti. Towards an 'ideal' approach for concept generation. Design Studies, 2003. ISSN 0142694X. https://doi.org/10.1016/S0142-694X(03)00003-6.

[54] Gul E. Okudan and Shafin Tauhid. Concept selection methods - a literature review from 1980 to 2008. International Journal of Design Engineering, 2008. ISSN 1751-5874. https://doi.org/10.1504/ijde.2008.023764.

[55] Richard Gagnon, Louis Gosselin, and Stéphanie Armand Decker. Performance of a sequential versus holistic building design approach using multi-objective optimization. Journal of Building Engineering, 26:100883, 2019.

[56] Allison Bernett, Katharina Kral, and Timur Dogan. Sustainability evaluation for early design (seed) framework for energy use, embodied carbon, cost, and daylighting assessment. Journal of Building Performance Simulation, 14(2):95-115, 2021.

[57] Jonathan A. Wright, Heather A. Loosemore, and Raziyeh Farmani. Optimization of building thermal design and control by multi-criterion genetic algorithm. Energy and Buildings, 2002. ISSN 03787788. https://doi.org/10.1016/S0378-7788(02)00071-3.

[58] Griet Verbeeck and Hugo Hens. Life cycle optimization of extremely low energy dwellings. Journal of Building Physics, 2007. ISSN 17442591. https://doi.org/10.1177/1744259107079880.

[59] Sudip Kumar Pal, Atsushi Takano, Kari Alanne, Matti Palonen, and Kai Siren. A multiobjective life cycle approach for optimal building design: A case study in Finnish context. Journal of Cleaner Production, 2017. ISSN 09596526. https://doi.org/10.1016/j.jclepro.2016.12.018.

[60] Joshua Hester, Jeremy Gregory, and Randolph Kirchain. Sequential early-design guidance for residential single-family buildings using a probabilistic metamodel of energy consumption. Energy and Buildings, 2017. ISSN 03787788. https://doi.org/10.1016/j.enbuild.2016.10.047.

[61] Xi Chen, Hongxing Yang, and Ke Sun. Developing a meta-model for sensitivity analyses and prediction of building performance for passively designed high-rise residential buildings. Applied Energy, 2017. ISSN 03062619. https://doi.org/10.1016/j.apenergy.2016.08.180.

[62] CY Ng, SS Lam, Samuel PM Choi, and Kris MY Law. Optimizing green design using ant colony-based approach. The International Journal of Life Cycle Assessment, 25(3):600-610, 2020.

[63] Vincent JL Gan, Chun Lok Wong, Kam Tim Tse, Jack CP Cheng, Irene MC Lo, and Chun Man Chan. Parametric modelling and evolutionary optimization for cost-optimal and low-carbon design of high-rise reinforced concrete buildings. Advanced Engineering Informatics, 42:100962, 2019.

[64] Yujie Cang, Zhixing Luo, Liu Yang, and Bing Han. A new method for calculating the embodied carbon emissions from buildings in schematic design: Taking "building element" as basic unit. Building and Environment, 185:107306, 2020.

[65] Rúben Santos, Antonio Aguiar Costa, Jose D Silvestre, Thomas Vandenbergh, and Lincy Pyl. Bim-based life cycle assessment and life cycle costing of an office building in western europe. Building and Environment, 169:106568, 2020.

[66] Carmen Llatas, Bernardette Soust-Verdaguer, and Alexander Passer. Implementing life cycle sustainability assessment during design stages in building information modelling: From systematic literature review to a methodological approach. Building and Environment, page 107164, 2020.

[67] Tajda Potrč Obrecht, Martin Röck, Endrit Hoxha, and Alexander Passer. Bim and lca integration: A systematic literature review. Sustainability, 12(14):5534, 2020. 
[68] Kailun Feng, Weizhuo Lu, and Yaowu Wang. Assessing environmental performance in early building design stage: An integrated parametric design and machine learning method. Sustainable Cities and Society, 2019. ISSN 22106707. https://doi.org/10.1016/j.scs.2019.101596.

[69] Madeleine M Flint, Matthew R. Eatherton, Georg Reichard, Guney C. Olgun, Roberto T. Leon, and Mohsen Zaker Esteghamati. Building information and structural models of archetype commercial buildings located in the central and eastern united states. 2021. https://doi.org/https://doi.org/10.17603/ds2-4k0j-nq17.

[70] International Organization for Standardization. Environmental Management: Life Cycle Assessment; Principles and Framework, volume 14044. ISO, 2006.

[71] Vaclav Hasik, Maximilian Ororbia, Gordon P. Warn, and Melissa M. Bilec. Whole building life cycle environmental impacts and costs: A sensitivity study of design and service decisions. Building and Environment, 2019. ISSN 03601323. https://doi.org/10.1016/j.buildenv.2019.106316.

[72] Athena Sustainable Materials Institute. User manual and transparency document. Technical report, 2019. URL https://calculatelca.com/wp-content/uploads/2019/05/IE4B_v5.4_ User_Guide_May_2019.pdf

[73] Ashley Edelen and Wesley Ingwersen. Guidance on data quality assessment for life cycle inventory data. US EPA, Cincinnati, Ohio, USA, 2016.

[74] Bo Pedersen Weidema and Marianne Suhr Wesnæs. Data quality management for life cycle inventories-an example of using data quality indicators. Journal of Cleaner Production, 1996. ISSN 09596526. https://doi.org/10.1016/S0959-6526(96)00043-1.

[75] Technical report.

[76] Martin Röck, Marcella Ruschi Mendes Saade, Maria Balouktsi, Freja Nygaard Rasmussen, Harpa Birgisdottir, Rolf Frischknecht, Guillaume Habert, Thomas Lützkendorf, and Alexander Passer. Embodied ghg emissions of buildings-the hidden challenge for effective climate change mitigation. Applied Energy, 258:114107, 2020.

[77] Jamie DeCoster. Testing group differences using t-tests, anova, and nonparametric measures. Accessed December 2021, 30(2010):202006-0, 2006.

[78] Andrew N Christopher. Interpreting and using statistics in psychological research. SAGE Publications, 2016.

[79] Peter D Hoff. A first course in Bayesian statistical methods, volume 580. Springer, 2009.

[80] Don Van Ravenzwaaij, Pete Cassey, and Scott D Brown. A simple introduction to markov chain monte-carlo sampling. Psychonomic bulletin \& review, 25(1):143-154, 2018.

[81] Dani Gamerman and Hedibert F Lopes. Markov chain Monte Carlo: stochastic simulation for Bayesian inference. CRC Press, 2006.

[82] Mohsen Zaker Esteghamati and Madeleine M Flint. Developing data-driven surrogate models for holistic performance-based assessment of mid-rise rc frame buildings at early design. Engineering Structures, 245:112971, 2021.

[83] Mohsen Zaker Esteghamati, Jeonghyun Lee, Matthew Musetich, and Madeleine M Flint. Inssept: An open-source relational database of seismic performance estimation to aid with early design of buildings. Earthquake Spectra, 36(4):2177-2197, 2020.

[84] National Ready Mix Concrete Association. Nrmca member industry-wide epd for ready mixed concrete. Technical report, 2016. URL https://www.nrmca.org/wp-content/uploads/2020/ 02/EPD10080.pdf.

[85] World Steel Association. Life cycle inventory methodology report. Technical report, 2016. URL https://www.worldsteel.org/en/dam/jcr:6eefabf4-f562-4868-b919-f232280fd8b9/ LCI+methodology+report_2017_vfinal.pdf.

[86] World Steel Association. Life cycle inventory (lci) study. Technical report, 2020. URL https://www. worldsteel.org/en/dam/jcr:5130acff-9564-4610-8563-04f118ba1e28/ 2020\%2520LCI\%2520study\%2520report_vf.pdf. 